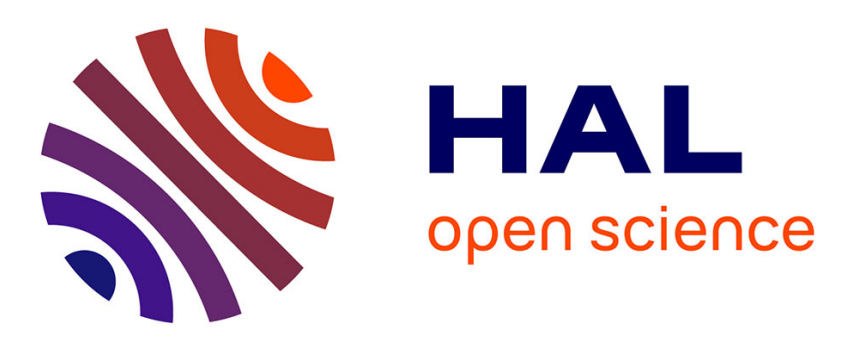

\title{
Child droplets from micro-explosion of emulsion and immiscible two-component droplets
}

Pavel Strizhak, Roman Volkov, Omar Moussa, Dominique Tarlet, Jérôme

Bellettre

\section{- To cite this version:}

Pavel Strizhak, Roman Volkov, Omar Moussa, Dominique Tarlet, Jérôme Bellettre. Child droplets from micro-explosion of emulsion and immiscible two-component droplets. International Journal of Heat and Mass Transfer, 2021, 169, pp.120931. 10.1016/j.ijheatmasstransfer.2021.120931 . hal03126714

\section{HAL Id: hal-03126714 https://hal.science/hal-03126714}

Submitted on 25 Mar 2021

HAL is a multi-disciplinary open access archive for the deposit and dissemination of scientific research documents, whether they are published or not. The documents may come from teaching and research institutions in France or abroad, or from public or private research centers.
L'archive ouverte pluridisciplinaire HAL, est destinée au dépôt et à la diffusion de documents scientifiques de niveau recherche, publiés ou non, émanant des établissements d'enseignement et de recherche français ou étrangers, des laboratoires publics ou privés. 


\title{
Child droplets from micro-explosion of emulsion and immiscible two-component droplets
}

Pavel Strizhak ${ }^{1 *}$, Roman Volkov ${ }^{1}$, Omar Moussa ${ }^{2}$, Dominique Tarlet ${ }^{2}$, Jérôme Bellettre ${ }^{2}$

${ }^{1}$ Heat Mass Transfer Simulation Laboratory, National Research Tomsk Polytechnic University, Russia, 30, Lenin Avenue, Tomsk, 634050, Russia. +7(3822)701-777, ex. 1910.

${ }^{2}$ Laboratoire de Thermique et Énergie de Nantes (LTeN), CNRS UMR 6607, Université de Nantes, Rue Christian Pauc, BP 50609, 44306 Nantes cedex 3, France.

*E-mail: pavelspa@tpu.ru

\begin{abstract}
Here we present the experimental findings of the research into the integral characteristics of secondary droplets produced from the micro-explosive fragmentation of two types of initial droplets. Both types are based on water and tetradecane: an emulsion droplet and a two-component immiscible droplet with water as the core and tetradecane as the envelope. We study the threshold (critical) conditions for the microexplosion of droplets on a substrate heated up to $550{ }^{\circ} \mathrm{C}$. In the course of experiments, we recorded the number, sizes, velocities, temperatures, and component composition of child droplets. It is shown that the parameters of child droplets differ significantly in the case of two-component droplets and emulsion droplets. The decisive impact comes from the heating temperature. Using a combination of Schlieren Photography, Particle Tracking Velocimetry, and 2-Color Laser Induced Fluorescence, we have determined the proportions of the concentration and size of secondary water droplets and combustible component droplets in the emerging aerosol cloud. We have also calculated the kinetic energies of child droplets. When generalizing the experimental findings, we established the conditions for the generation of a high-temperature fine mist aerosol through the micro-explosive breakup of two-component droplets and recorded the typical trajectories of secondary fragments. We show that such conditions are possible for both emulsion droplets and immiscible two-component droplets with a pronounced interface. It is established that much more secondary fragments of water are produced in the second case. This result shows that water separates from the combustible component more intensely in the second case, and the micro-explosion systems relying on water and combustible liquid droplets mixing in the combustion chamber bear more promise.
\end{abstract}

Keywords: micro-explosion; two-component droplet; emulsion; child droplets; schlieren photography; 2Color LIF.

\section{Nomenclature}

$E_{\text {ch-d }}$ - average kinetic energy of child droplets (J);

$i$ - number of groups of child droplet radii; 
$k_{1}, . ., k_{\mathrm{m}}-$ number of analyzed frames in each specific experiment;

$m$ - number of experiments;

$m_{\text {ch-d }}-$ average mass of child droplets $(\mathrm{kg})$;

$n$ - average relative number of all child droplets in one frame;

$n$ (water) - average quantity and average volume fraction of water droplets in the total number of emerging child droplets (\%);

$N$ - absolute average number of droplets of each size

$N_{1}, . ., N_{\mathrm{m}}$ - total number of droplets with each radius in each specific experiment;

$N_{\mathrm{pf}}$ - specific number of child droplets of each size in one frame;

$N_{\mathrm{pf}(1), . .,} N_{\mathrm{pf}(\mathrm{m})}$ - number of droplets with this radius in each specific experiment (per frame);

$p$ - number of points used to obtain the average value of $T_{\text {ch-d; }}$;

$R_{\text {ch-d }}$ - radius of child droplets $(\mathrm{mm})$;

$R f$ - Fluorescence Ratio;

$t$ - time (s);

$t_{\mathrm{e}}$ - average droplet lifetime (s);

$T_{\mathrm{br}}$ - temperatures in the area that does not contain the Rhodamine B fluorophore determined from the luminosity of the background $\left({ }^{\circ} \mathrm{C}\right)$;

$T_{\text {ch-d }}-$ temperature of child droplets $\left({ }^{\circ} \mathrm{C}\right)$;

$T_{\text {ch-d(1) }}, T_{\text {ch-d(2) }}, T_{\text {ch-d(p) }}-$ temperatures for each moment of time $\left({ }^{\circ} \mathrm{C}\right)$;

$T_{\text {surf }}$ - temperature of the heated surface $\left({ }^{\circ} \mathrm{C}\right)$;

$U_{\text {ch-d }}$ - velocity of child droplets $(\mathrm{m} / \mathrm{s})$;

$V_{\text {sum }}$ - total average volume of child droplets in one frame $\left(\mathrm{mm}^{3}\right)$.

\section{Greek symbols}

$\rho$ - water density at $T_{\text {ch-d }}\left(\mathrm{kg} / \mathrm{m}^{3}\right)$.

\section{Abbreviation}

LIF - Laser Induced Fluorescence;

LIP - Laser Induced Phosphorescence;

PLIF - Planar Laser Induced Fluorescence;

PTV - Particle Tracking Velocimetry;

SP - Schlieren Photography.

\section{Introduction}

The micro-explosive fragmentation of liquid droplets is a subject of active research and development focusing on the intense dispersion of droplets when they reach the boiling temperature of water that they contain [1-3]. The experiments in Refs. [1-3] confirm that two-component droplets are 
enough to provide micro-explosive fragmentation. A liquid combustible component and water can be used as both the envelope and core of the droplet. The greater the difference between the boiling temperatures of the combustible and non-combustible liquid components, the more intense the microexplosion. It was also experimentally established that micro-explosion occurs with emulsions, micro-, and nano-emulsions [4-8], as well as with a heated immiscible two-component droplet (i.e., with one pronounced inter-component interface) [9-11]. The use of technologies based on droplet microexplosions affects the economic, environmental, energetic, rheological, and other parameters of the corresponding processing chambers and the processes occurring therein [12-16]. The spraying and secondary atomization of fuel droplets in combustion chambers can be considered the main application $[17,18]$. Primary spraying systems based on injectors, spray nozzles, etc. are limited in terms of the resulting aerosol particle size distribution. However, the secondary atomization of droplets within a chamber can be arranged in the most favorable zone to intensify the corresponding reactions. Microexplosions increase the thermal power of the corresponding units and plants due to a several-fold increase in the liquid surface area. Thus, the reaction area of the fuel with the heated gas medium is enlarged. Less time is needed for its heating, evaporation, and interaction with the oxidizer. The fuel combustion becomes more complete; hence lower physical and chemical underburning. In the present work, the micro-explosive breakup of liquid droplets is considered in the context of secondary atomization of fuel droplets. For instance, with the limited size of the combustion chamber, atomized fuel droplets hit the chamber walls. Knowing the special aspects and conditions required for the micro-explosive breakup and taking into account the wall temperature, one can specify the necessary proportion of components and the droplet structure (emulsion droplets or immiscible two-component droplets) to provide droplet atomization. Knowing the micro-explosive times, one can choose the delay between fuel injections to provide full breakup of droplets and further combustion of the fuel.

Some research groups, e.g., Khan et al. [13], published the findings of their research into microexplosive effects based on a wide range of compositions, such as dodecane, tetradecane, hexadecane, diesel, kerosene, different oils, etc. The researchers recorded critical (i.e., minimal and sufficient) conditions of a micro-explosion for all of those compositions. However, despite the abundance of wellknown papers reflecting the research findings on micro-explosive droplet fragmentation [1-13], most of them determine the critical (boundary) conditions of a micro-explosion with varying key parameters in a wide range, accounting for the decisive effects: component composition of a droplet [13], heating mechanism and scheme [11], external gas medium properties and temperature [9-11], original droplet size [9-13], etc. Other popular subjects are the characteristics of micro-explosion, in particular, the atomization mechanism [3, 9, 13], the duration of micro-explosive fragmentation [10], droplet temperature before the explosion [8, 9, 14], droplet heating rates [9], etc. In practice, however, the main interest lies in the characteristics of child droplets resulting from the micro-explosion of the parent 
droplet. The research findings on those characteristics are given in Refs. [5, 10, 15, 16]. The authors of Refs. [10, 15, 16] determined the size distributions of child droplets. Tarlet et al. [5] experimentally determined the thermal energy of child droplets. Despite the known experimental results, there is yet no data on the comprehensive analysis of child droplet characteristics, such as sizes, velocities, trajectories, temperature, energy, and component composition. The corresponding experiments are difficult to arrange, because they require the simultaneous application of a set of methodologies that differ in the operating principles of the key equipment.

There is also a limited number of research findings (e.g., $[5,10,15,16])$ on the integral characteristics of child droplets, because the processes under study are fast-paced and their recording requires complex and expensive recording systems [1, 8, 9, 14, 19-28], as well as dedicated data processing algorithms. For instance, the key methods for recording the characteristics of child droplets are as follows: Particle Tracking Velocimetry (PTV) $[19,20]$ for the velocities and trajectories of child droplets; Schlieren Photography (SP) [21, 22] for their number and size; Laser Induced Phosphorescence (LIP) [23-25], Planar Laser Induced Fluorescence (PLIF) [9, 26, 27], and 2-Color Laser Induced Fluorescence (2-Color LIF) $[1,8,14,28]$ for their temperature. The methodologies for determining the velocities $[19,20]$ and sizes $[21,22]$ of child droplets are robust, while temperatures are recorded in rather sophisticated ways. To start with, not all of the above temperature diagnostic methods may be applicable to reliably determine the temperature of child droplets. For instance, LIP [23-25] involves adding phosphorescent particles that can absorb and emit ultraviolet radiation. In this case, a threecomponent droplet is formed rather than a two-component one. This may alter the micro-explosion characteristics [10], in particular, accelerate or slow down this process due to changes in the mean (or effective) thermal diffusivity. The particle size may reach 4-5 $\mu \mathrm{m}$ [23], while the sizes of newly formed child droplets may be as small as 10-20 $\mu \mathrm{m}$ or even smaller $[10,15,16]$, which makes it hard to ensure the uniform concentration of phosphorescent particles within the emerging child droplets. LIP can only give a good result if particles are relatively evenly distributed throughout the medium under study. In the case of fast-paced processes, however, even if droplets are relatively large (50-100 $\mu \mathrm{m})$ [11], the particle concentration may be too low for reliable measurements. Therefore, the LIF technique, where fluorophore is fully dissolved in a liquid, seems a good alternative for child droplet temperature recording $[1,8,9,14$, 26-28]. The PLIF technique [9, 26, 27] makes it possible to diagnose the liquid temperature provided that the fluorophore concentration and laser radiation power remain constant. In the case of micro-explosive droplet fragmentation, droplet evaporation and changing light sheet trajectory may affect the intensity of the radiation being absorbed and emitted. In addition, since droplets often move erratically on a heated solid surface, the measurement results seem impossible to adjust. In light of the above, the optimal approach to child droplet temperature diagnostics is the use of 2-Color LIF [1, 8, 14, 28]. One of the benefits of this approach lies in its insensitivity to changes in fluorophore concentration and laser 
radiation power. Moreover, 2-Color LIF has been used to determine the temperature of emulsion droplets and immiscible two-component droplets until their explosive fragmentation [8, 14]. In Ref. [14], we observe the coalescence of water micro-droplets in emulsion droplets and intense disruption of the water core in a heated two-component droplet. The most important experimental result [14] is that we have confirmed our earlier hypothesis that emulsion and immiscible two-component droplets have rather similar temperature fields. It is shown [14] that at the heating stage, the temperature differences in twocomponent droplets were much lower than in an emulsion droplet due to the uneven water distribution in a droplet. Here the temperature difference could range from $1{ }^{\circ} \mathrm{C}$ to $10^{\circ} \mathrm{C}$. The average droplet temperature in the puffing regime was about $1-3{ }^{\circ} \mathrm{C}$ higher than in the micro-explosion regime at the same heating temperatures. The experimental research of such processes became possible using 2-Color LIF. The difference between micro-explosion and puffing largely lies in the intensity of the destruction process, as well as the sizes of the resulting child droplets [14, 29, 30]. The puffing regime is characterized by the gradual destruction of a droplet throughout the time of its heating with rather large fragments breaking off, so this is a partial destruction of the droplet. The micro-explosion regime is characterized by the full breakup of the parent droplet into small child droplets (sized less than $150 \mu \mathrm{m}$ ).

Thus, it is advisable to use a combination of SP, PTV, and 2-Color LIF to determine the number, size, velocities, trajectories, temperatures, component compositions, and energies of child droplets emerging from the micro-explosive fragmentation of original heterogeneous droplets. These results will make it possible to supplement the research findings from Ref. [14], analyze the above characteristics in totality, as well as establish a link between these parameters and provide a deeper insight into the processes of micro-explosive liquid droplet fragmentation [1-16]. When generalizing the experimental results, one will be able to single out the most promising avenues for optimizing the characteristics of child droplets with different compositions of initial fuel droplets and their heating conditions.

The purpose of this research is to experimentally study the number, sizes, velocities, trajectories, component compositions, temperatures, and energies of child droplets resulting from the micro-explosive breakup of two types of parent droplets: emulsions and immiscible two-component droplets. The research builds on our earlier paper [14] and provides a deeper insight into the micro-explosive breakup of heterogeneous liquid droplet in contact with a substrate heated up to high temperatures. In [14], we described the threshold conditions for the occurrence of micro-explosions and partial fragmentation of fuel droplets with identical component compositions. However, the characteristics of the emerging fragments were beyond the scope of that research.

\section{Materials and types of droplets}

The heterogeneous fuel-water droplets consisted of tetradecane $\left(\mathrm{CH}_{3}\left(\mathrm{CH}_{2}\right)_{12} \mathrm{CH}_{3}\right)$ and tap water with the Rhodamine $B$ fluorophore $\left(\mathrm{C}_{28} \mathrm{H}_{31} \mathrm{ClN}_{2} \mathrm{O}_{3}\right)$ (in a mass concentration of $3 \mathrm{~g} / \mathrm{l}$ ) [14]. The 
experiments were performed for the two types of subjects as in Ref. [14]: a two-component immiscible droplet and a droplet of pre-fabricated emulsion. In both cases, a droplet contained $91 \%$ of the combustible component (tetradecane) and $9 \%$ of water (Table 1). The main properties of the combustible component (Sigma-Aldrich, No. 172456) were as follows: refractive index 1.429; boiling temperature $252-254{ }^{\circ} \mathrm{C}$; density $0.762 \mathrm{~g} / \mathrm{mL}$ at $20^{\circ} \mathrm{C}$.

At the first stage, we prepared a solution of water and Rhodamine B. After that, Rhodamine B crystals were weighed in the necessary amount on a laboratory micro-balance with an increment of $0.0001 \mathrm{~g}$. Rhodamine B was then mixed with water for $10 \mathrm{~min}$ using an automatic mixer (VMS-C4). The initial temperature of the sessile droplet was about $25 \pm 1{ }^{\circ} \mathrm{C}$.

An emulsion droplet was prepared in the following way [14]:

(i) using an automatic VMS-C4 mixer, we continuously mixed a water solution of Rhodamine B and tetradecane;

(ii) in the course of mixing (15 min after the mixing process began), we collected the emulsion using a syringe with a needle, about $0.4 \mathrm{~mm}$ in the internal diameter;

(iii) with the same syringe and needle, we generated a droplet of about $5.5 \mu 1$ (radius $R_{\mathrm{d}} \approx 1.1 \mathrm{~mm}$ ), which was placed on a metal substrate.

A two-component immiscible droplet was generated in the following way [14]:

(i) using a single-channel micro-dispenser that can generate droplets in the range of 2.5-50 $\mu 1$ with an increment of $0.1 \mu 1$, we produced a tetradecane droplet of $5 \mu 1$, which was fixed on a thin steel holder, $0.6 \mathrm{~mm}$ in diameter;

(i) using another single-channel micro-dispenser, also generating 2.5-50- $\mu 1$ droplets with an increment of $0.1 \mu 1$, we produced a Rhodamine B water solution droplet with a volume of $0.5 \mu 1$, which was added to the tetradecane droplet;

(iii) an immiscible two-component droplet with a total volume of $5.5 \mu 1$ and mean radius $R_{\mathrm{d}} \approx 1.1 \mathrm{~mm}$ was discharged from the holder to the metal substrate.

Table 1. Average volumetric fractions and average water droplet size in the droplet under study.

\begin{tabular}{|l|c|c|c|c|c|}
\hline Type of fuel-water droplet & $\begin{array}{c}\text { Fuel } \\
\text { volume }\end{array}$ & $\begin{array}{c}\text { Water } \\
\text { volume }\end{array}$ & $\begin{array}{c}\text { Droplet } \\
\text { volume }\end{array}$ & $\begin{array}{c}\text { Droplet } \\
\text { radius }\end{array}$ & $\begin{array}{c}\text { Fuel volumetric } \\
\text { fraction }\end{array}$ \\
\cline { 1 - 3 } Immiscible two-component & $5.0 \mu \mathrm{l}$ & $0.5 \mu \mathrm{l}$ & $5.5 \mu \mathrm{l}$ & $1.1 \mathrm{~mm}$ & $91 \%$ \\
\cline { 1 - 3 } Emulsion & - & - & & \\
\hline
\end{tabular}

In actual applications, such as fuel combustion, droplet size may vary in a wide range. For example, when fuel is burned in internal combustion chambers, droplet diameters may range from 5 to $180 \mu \mathrm{m}[31,32]$, depending on the type and design of the atomizer used. However, when slurry fuels (for 
instance coal water slurries) are burned in boiler unit furnaces, the droplet size may be both $40-250 \mu \mathrm{m}$ [33] and increase up to several millimeters [34] depending on the component concentration and viscosity of the composition. The size of a primary droplet $\left(R_{\mathrm{d}} \approx 1.1 \mathrm{~mm}\right)$ is in fact larger by an order of magnitude (Table 1) than the size of droplets that are normally burned in internal combustion chambers [31]. However, as mentioned earlier, one of the purposes of this research is to study the atomization process and characteristics of the resulting child droplets. This mechanism is proposed as an alternative to mechanical atomization of a composition using pulverizers [31-34]. First, large droplets, several millimeters in size, can be generated using pulverizers of simpler design and lower pressures. Secondary atomization of droplets due to their micro-explosive breakup can provide the size (see section 4.3 for analysis), which is comparable to that of droplets obtained using special-purpose pulverizers [31]. Second, smaller size makes it difficult to produce immiscible two-component droplets with the required component concentration. Thus, the research focuses on the size of the resulting child droplets rather than parent droplets.

\section{Experimental methods}

\subsection{Main elements of setup}

The experimental setup featured the following key elements: a continuous-wave laser SpectraPhysics Millennia eV with an output power of $10 \mathrm{~W}$ and wavelength of $532 \mathrm{~nm}$; a LED spotlight $(\sim 10 \mathrm{~W}$, $\sim 800 \mathrm{Lm})$; a high-speed video camera Photron FASTCAM SA-X2 (13.5 kHz at the maximum possible resolution of $1024 \times 1024$ pix); a set of two optical lenses to transform a laser beam into a light sheet for droplet cutting; a metal substrate with a cavity to fix a two-component droplet under study; a power supply TDK-Lambda Z320-1.3-U delivering the current to the heating element fixed under the substrate (Fig. 1) and transferring the thermal energy to it; image splitting optics W-VIEW GEMINI A12801-01 to double the signal from the subject to be recorded. The setup was equipped with a 580-600-nm dichroic mirror and two color filters to single out the necessary wavelength in each recording channel: $580 \pm 5 \mathrm{~nm}$ and $620 \pm 5 \mathrm{~nm}$.
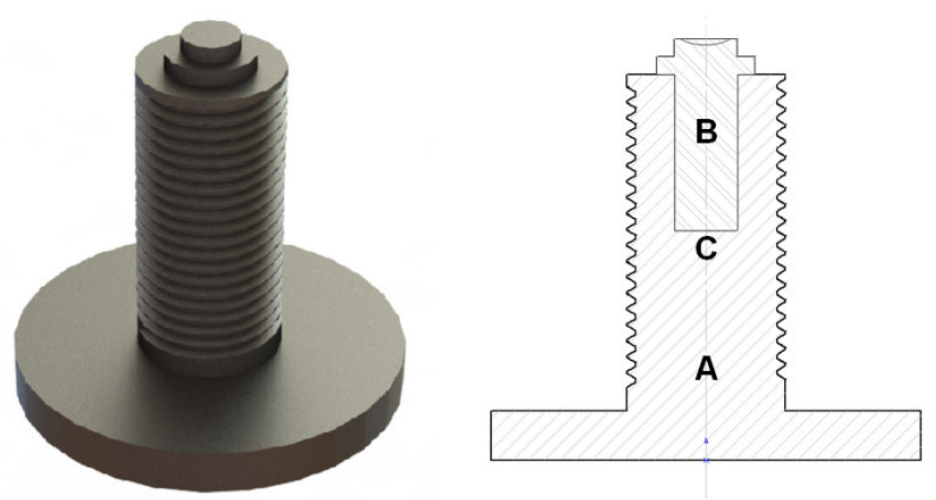

Fig. 1. Schematic image of the heating substrate [14]: A - threaded support for the hot wire; B - droplet holder; $\mathrm{C}$ - position of the $80 \mu \mathrm{m}$ K-type thermocouple. 


\subsection{Recording the temperature $\left(T_{\text {ch-d }}\right)$ of child droplets}

At the initial experimental stage, the 2-Color LIF technique was temperature-calibrated. The calibration process was described in Refs. $[8,14]$. Temperature calibration was carried out on a water droplet with Rhodamine B placed into silicone oil of a fixed temperature. The support and the drop are embedded in a silicone oil bath. The silicone oil was selected for two reasons [14]. The first is the high viscosity of the medium (it was about $500 \mathrm{~mm}^{2} / \mathrm{s}$ ). This prevented the water droplet motion in the oil bath. The second reason is the absorption spectrum of visible radiation by the silicone oil. Silicone oil absorption (and excitation) is negligible in the wavelength range we are interested in (532-650 nm), and thus it would not affect the measurements [14]. As the first step, we recorded the video frames of the water droplet at different temperatures of the silicone oil. The temperatures of the water droplet and silicone oil were assumed to be comparable (based on thermo-physical simulations and order of magnitudes). This assumption is supported by the fact that we waited for almost 15-20 minutes after fixing the oil temperature. The temperature of silicone oil was recorded by a thermocouple immersed in it. As the second step, Fluorescence Ratio $(R f)$ was determined and compared with the water temperature values obtained earlier. The calibration curve $R f=f(T)$ was plotted. The calibration curve equation was a second order polynomial: $R f=-9 \cdot 10^{-5} \cdot T-0.0063 \cdot T+2.8499$.

The temperature of the child droplets was measured using a setup schematically shown in Fig. $2 a$.

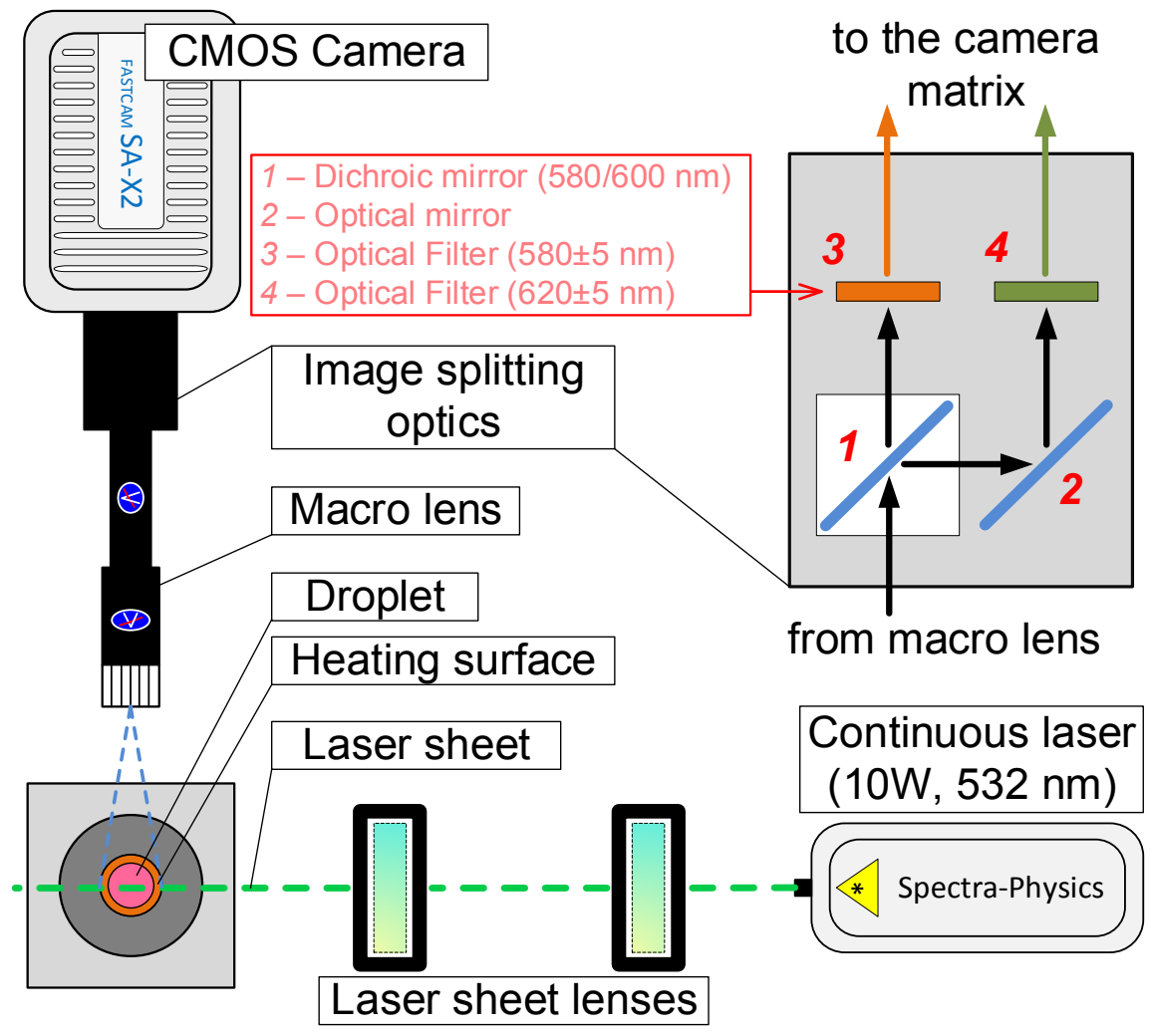



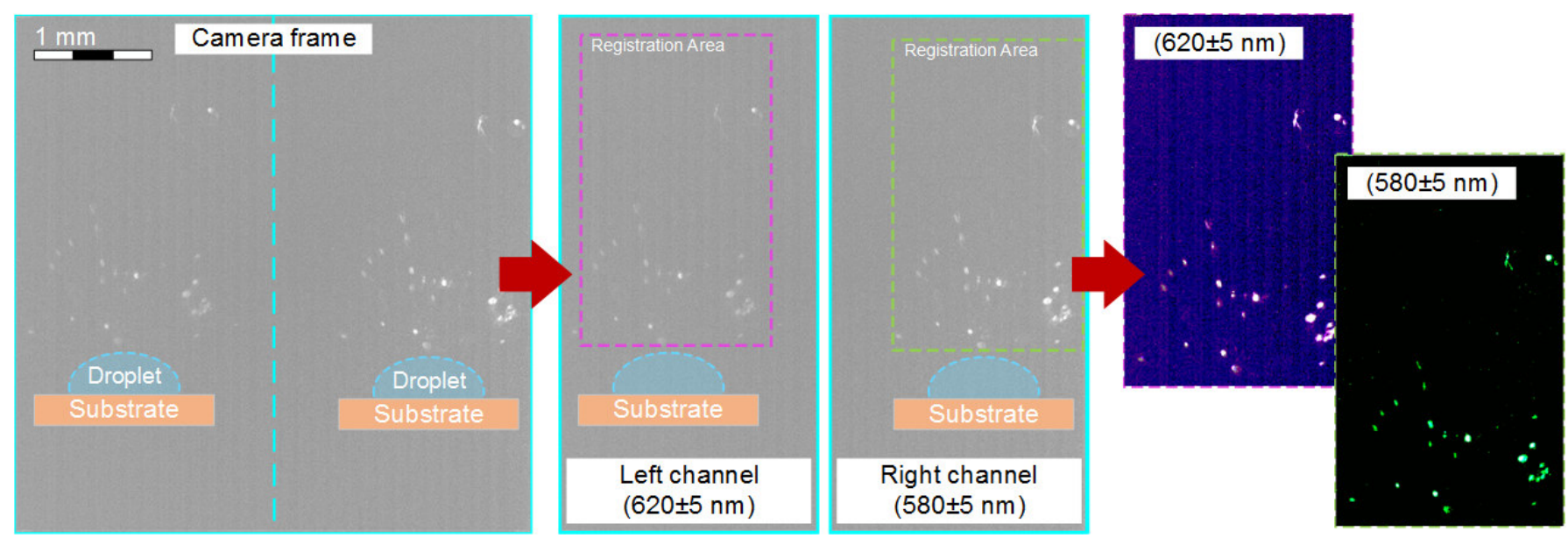

$b$

Fig. 2. $a$ - configuration of experiments on child droplet temperature recording; $b$ - scheme of initial frame separation into two images.

Each experiment involved several consecutive stages:

(i) using a TDK-Lambda Z320-1.3-U, we supplied the required current to the heating element so as to achieve the necessary temperature $\left(T_{\text {surf }}\right)$ on the metal substrate (Fig. 1) (in the range of 150$\left.550{ }^{\circ} \mathrm{C}\right)$;

(ii) a $532 \mathrm{~nm}$ (for the absorption wavelength) laser generated a beam which was converted into a light sheet (thickness is around $500 \mu \mathrm{m}$ ) by a system of two lenses; the light sheet cut the area above the substrate along its vertical axis (Fig. 1); The laser power was $5 \mathrm{~W}$;

(iii) the area above the metal substrate was recorded by a high-speed video camera (frame rate $5000 \mathrm{fps}$, exposure time $1 / 8000 \mathrm{~s}$, resolution $612 \times 612 \mathrm{pix}$ );

(iv) the droplet (Fig. 1) was discharged onto the substrate;

(v) the process was recorded using the Photron FASTCAM Viewer software package until the droplet broke up in the micro-explosion or puffing regimes.

The videos were saved as a set of consecutive frames. The physical size of the original image (with a camera resolution of $612 \times 612$ pix) was about $17.44 \times 17.44 \mathrm{~mm}$ (with a scale factor of 0.0285 $\mathrm{mm} / \mathrm{pix})$. After that, they were processed and the temperature of child droplets $\left(T_{\text {ch-d }}\right)$ was calculated.

Each frame was split into two independent images sized $306 \times 612$ pix: the left $(620 \pm 5 \mathrm{~nm})$ and right $(580 \pm 5 \mathrm{~nm})$ channels, similar to [14] (Fig. 2b). The final pairs of images (Fig. 2b) were imported into the DaVis software package. The data was further processed (using one experiment as an example) in several consecutive stages:

(i) The images of the droplet from the left $(620 \mathrm{~nm})$ and right $(580 \mathrm{~nm})$ channels were aligned using a flat calibration target with coplanar vectors obtained when the system was tuned; the marker was $1 \mathrm{~mm}$ in diameter and the distance between the centers of markers was $1.5 \mathrm{~mm}$ (Image Correction). 
(ii) We analyzed the temporal variations in the average intensity of the image background. The average background intensity in the images mostly varied around a constant, specific to each experiment. The average background intensity obtained was subtracted from each image (Image Arithmetic).

(iii) The luminosity ratio (Fluorescence Ratio $(R f)$ ) was determined for each pixel in the pair of frames $(580 / 620 \mathrm{~nm})$. The calibration process is precisely described in paragraph 3 of Ref. [8], using a droplet of water mixed with Rhodamine B placed in a fixed-temperature silicone oil. First, video frames of the water droplet were recorded at various temperatures of silicone oil, assuming that the temperatures of the drop of water and silicone oil (measured by means of a thermocouple) are comparable. Secondly, the sequence of operations was performed, which is described in detail in the "data processing" section in paragraphs (i) - (iii). After that, the found values of the Fluorescence Ratio $(R f)$ were compared with the previously obtained values of the water temperature, resulting in a calibration curve $R f=f(T)$ in the form of a second-order polynomial: $R f=-9 \cdot 10^{-5} \cdot T-0.0063 \cdot T+2.8499$. As a result, we obtained the image of one droplet (and separate child droplets) at each moment of time. The luminosity of each droplet in that image was a function of the liquid temperature (Two Color LIF).

(iv) The Fluorescence Ratio obtained as the previous step was converted into temperature with the help of the calibration curve equation. Thus we obtained a two-dimensional temperature field (LIF Temperature Calculation). However, if the $R f$ value obtained went beyond the calibration curve, this point was not assigned a temperature value.

(v) The temperature field was smoothed to obtain a uniform picture $(3 \times 3$ Smoothing Filter). More precisely, the final temperature of each pixel in the image is the arithmetic average of the 9 surrounding pixels, which neutralizes the erroneous peaks (highs and lows) of the temperature in the final distribution.

When all the images were processed, we calculated the variation in the average temperature of child droplets as well as the temperature of child droplets at different distances from the heating surface. Fig. 3 schematically reflects the areas used for the calculation of the temperatures mentioned above. As part of the calculation, we averaged the droplet temperature (Average Processing) at each point of time: we determined the arithmetic mean of the temperatures of all the points in the highlighted area. After that, we determined the average temperature of the highlighted area versus time.

Due to the re-reflection of the laser beam from the droplet and substrate, the background intensity sometimes exceeded the average value obtained at stage ii (Image Arithmetic). Therefore, the temperatures $T_{\mathrm{br}}$ were detected even in the area that did not contain Rhodamine $\mathrm{B}$, which required plotting an extra curve (like in Ref. [14]) to describe the temporal variation in the average temperature $T_{\text {br }}$. After that, we calculated the difference $T_{\text {ch-d }}-T_{\text {br }}$ for each moment of time. When $T_{\text {ch-d }}-T_{\text {br }}<20{ }^{\circ} \mathrm{C}$, the point was excluded from the analysis. Fig. 4 shows the functions $T_{\mathrm{ch}-\mathrm{d}}=f(t)$ before and after filtration.

After that we calculated the time-average temperatures of child droplets in the highlighted regions (Area\#1, Area\#2, Area\#3, Complete Area) for each temperature of the substrate $\left(T_{\text {surf }}\right): T_{\text {ch-d }}=\left(T_{\text {ch-d(1) }}+T_{\text {ch- }}\right.$ 


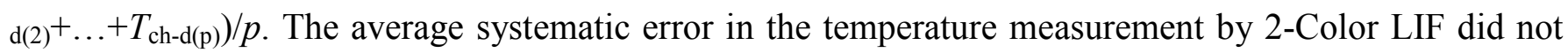
exceed $5{ }^{\circ} \mathrm{C}$ [8]. Morphology dependent resonances (MDRs) or lasing effect were analyzed prior to research. Traditionally, this phenomenon manifests itself either with small (radius less than $50 \mu \mathrm{m}$ ) drops, or with relatively high specific powers of the laser radiation source. A detailed analysis (presented in [8]) shows that at a specific laser power of the order of $3.5 \mathrm{~W} / \mathrm{cm}^{2}$ and a size of the minimally detected individual droplets $R_{\mathrm{d}}=25-50 \mu \mathrm{m}$, the phenomena of laser resonance inside micro-droplets are minimal. As a consequence, these effects cannot significantly affect the error in estimating the temperature of child droplets.
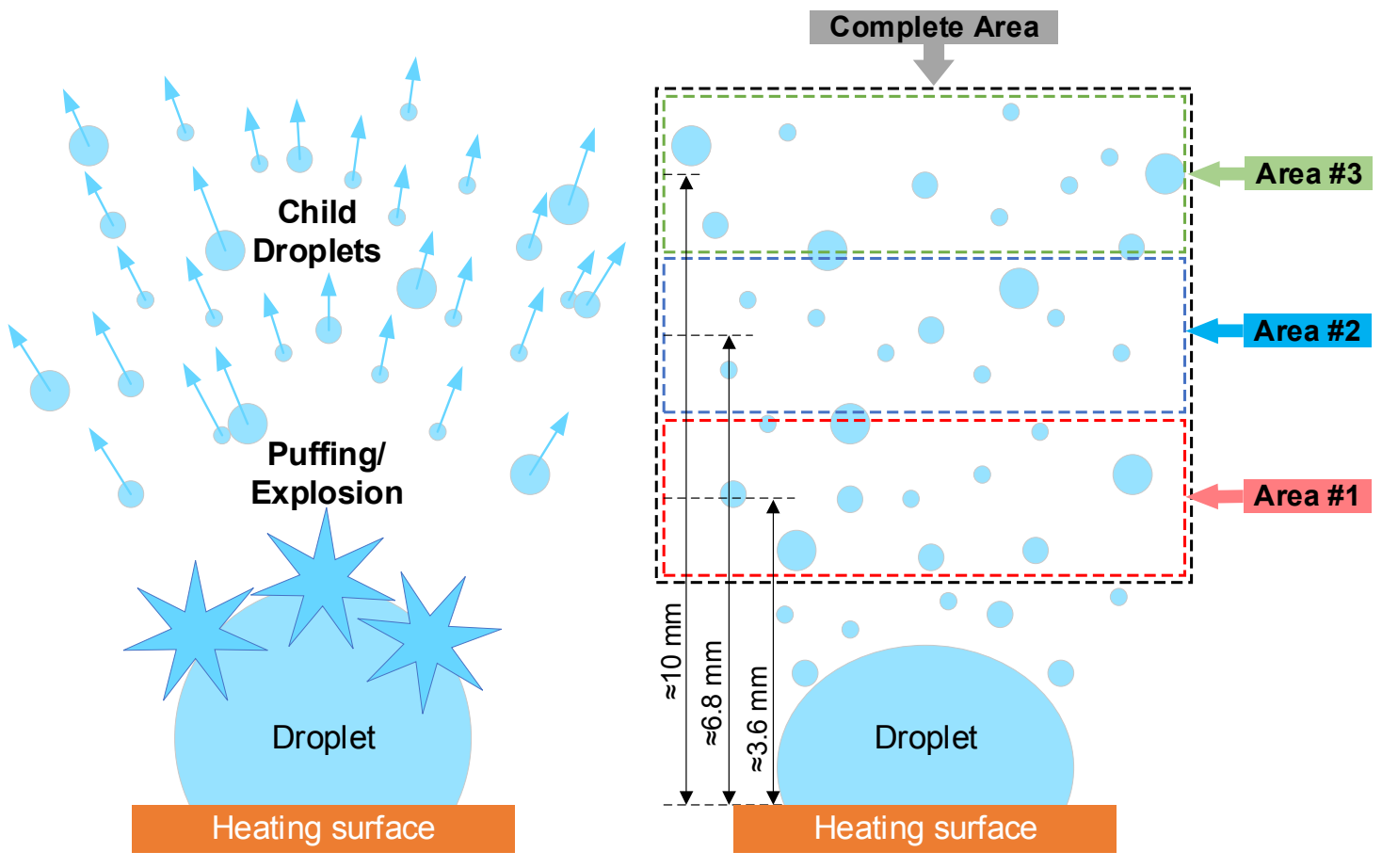

$a$

$b$

Fig. 3. $a$ - scheme of micro-explosive droplet breakup; $b$ - averaging regions used to determine the temperatures of child droplets.

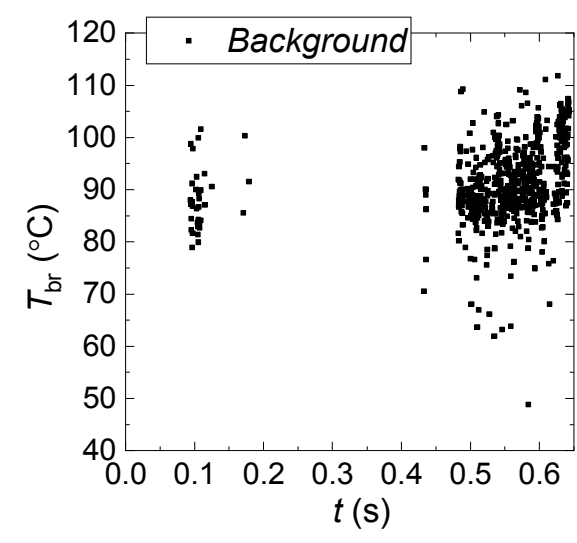

$a$

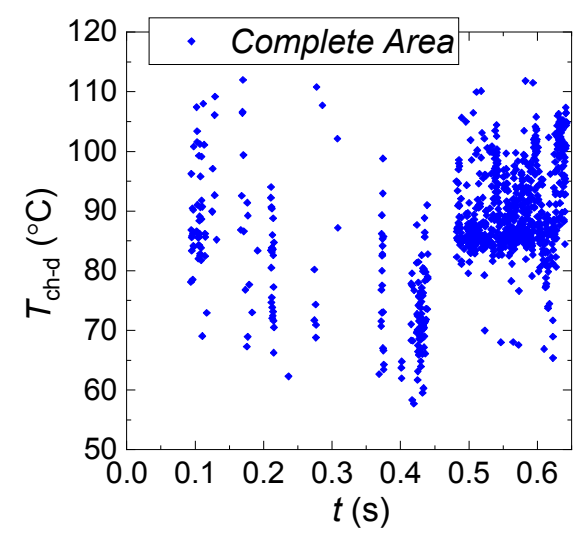

$b$

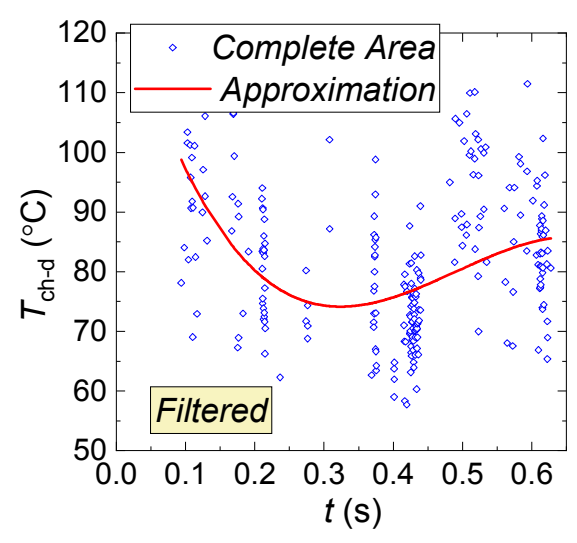

$c$

Fig. 4. $a$-temporal variation of $T_{\mathrm{br}} ; b$ - variation in the child droplet temperature (Complete Area) before filtration; $c$ - variation in the child droplet temperature (Complete Area) after filtration. 
3.3. Calculating the radii $\left(R_{\text {ch-d }}\right)$, component composition, and velocities $\left(U_{\text {ch-d }}\right)$ of the emerging child droplets

Fig. 5 shows the scheme of the experiments. Each experiment involved several consecutive stages:

(i) using a TDK-Lambda Z320-1.3-U, we supplied the required current to the heating element so as to achieve the necessary temperature $\left(T_{\text {surf }}\right)$ on the metal substrate (in the range of $150-550{ }^{\circ} \mathrm{C}$ );

(ii) in the case of laser illumination, a solid-state laser generated a beam, which was then converted into a light sheet by a system of two lenses; the light sheet cut the area above the substrate along its vertical axis (Fig. 5). In the case of schlieren photography, a LED light system generated a plane-parallel light beam directed towards the video camera lens (Fig. 5);

(iii) the region above the metal substrate was recorded by a high-speed video camera (frame rate $5000 \mathrm{fps}$, exposure time $1 / 8000 \mathrm{~s}$ for laser illumination and 1/160000 s for schlieren photography; resolution $-612 \times 612$ pix); resolution $612 \times 612$ pix);

(iv) the resulting droplet (stage 2) was discharged onto the substrate;

(v) the process was recorded using the Photron FASTCAM Viewer software package until the droplet broke up in the explosion or puffing regimes.

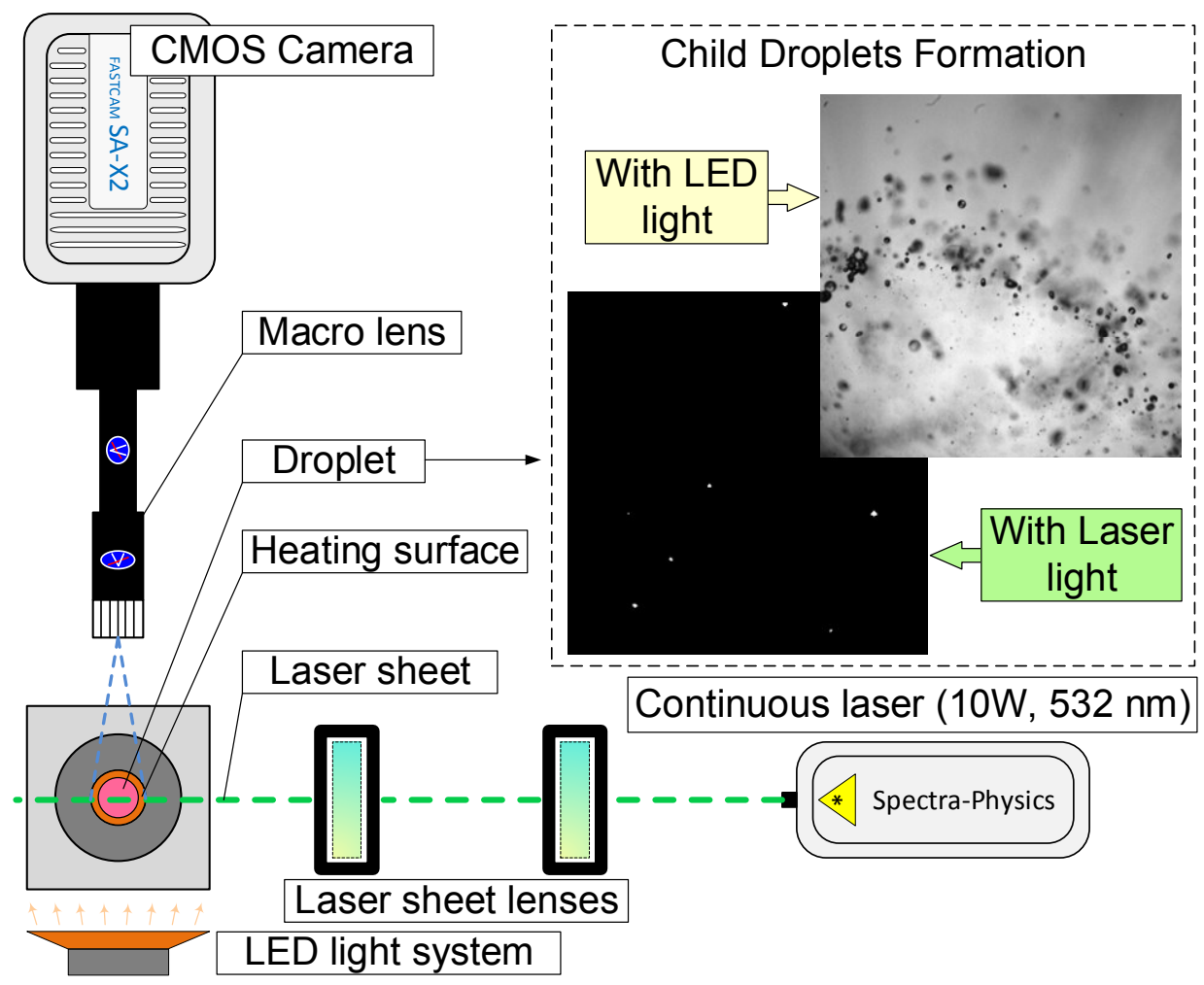

Fig. 5. Configuration of experiments recording the size, component composition, velocities, and trajectories of child droplets.

We did two series of experiments. In each series, at least five tests were performed for each group of parameters. The first one involved recording the characteristics of micro-explosive fragmentation of 
heterogeneous droplets illuminated by a laser (characteristics and size of droplets are detailed in section 2). In this case, the observational area was illuminated by a continuous-wave laser (532 nm). A color filter lens of $580 \pm 5 \mathrm{~nm}$ was installed on the video camera. This way we recorded the micro-droplets of water or droplets containing a water additive as soon as they started emitting light in the range of $580 \pm 5$ $\mathrm{nm}$ due to the Rhodamine B fluorophore in their composition. In this case, the water-containing droplets caught in the light sheet plane were recorded. The thickness of the light sheet in tests was about $0.5 \mathrm{~mm}$. In the second series of experiments, we recorded the characteristics of micro-explosive fragmentation of heterogeneous droplets using a background LED lighting. We used a LED spotlight installed opposite the video camera lens (Fig. 5). In this case, all the emerging child droplets were recorded. The droplets within the field depth of the lens (about $1.5 \mathrm{~mm}$ ) were recorded. The two types of experiments are required to indirectly determine the component composition of liquid fragments resulting from the micro-explosive fragmentation.

The videos were saved as a set of consecutive frames and processed. We calculated the radii $\left(R_{\text {ch- }}\right.$ d) and specific number $\left(N_{\text {pf }}\right)$ of child droplets. The images were imported into the ActualFlow software. The data were further processed in several consecutive stages using the Multiphase Kit software bundle.

The data obtained using laser illumination were processed in the following stages:

(i) smoothing the image to remove the noises $(3 \times 3$ Low Pass Filter);

(ii) binarizing the image obtained as the first step (Image Binarization). The binarization threshold was determined specifically for each experiment as the maximum intensity of the image background (noise). After that, the pixels of water droplets were assigned the intensity value of 255 and the rest of the pixels, the value of 0 ;

(iii) detecting the droplet edges (Laplace Edge Detection);

(iv) calculating the radii $\left(R_{\mathrm{ch}-\mathrm{d}}\right)$ of child droplets using the droplet edges detected as the previous step. Here we chose the binarization threshold corresponding to the intensity of the droplet edges detected and used the binarized image to identify simply connected domains (Bubbles Identification);

(v) plotting droplet size distribution histograms and calculating the time-average radii $\left(R_{\text {ch-d }}\right)$ of child droplets for each temperature of the heated surface $\left(T_{\text {surf }}\right)$.

The data obtained using schlieren photography were processed in the following stages:

(i) smoothing the image to remove the noises $(3 \times 3$ Low Pass Filter);

(ii) detecting the droplet edges (Laplace Edge Detection);

(iii) calculating the radii $\left(R_{\mathrm{ch}-\mathrm{d}}\right)$ of child droplets using the droplet edges detected as the previous step. Here we chose the binarization threshold corresponding to the intensity of the droplet edges detected and used the binarized image to identify simply connected domains (Bubbles Identification);

(iv) plotting droplet size distribution histograms and calculating the time-average radii $\left(R_{\mathrm{ch}-\mathrm{d}}\right)$ of child droplets for each temperature of the heated surface $\left(T_{\text {surf }}\right)$. 
Video frames obtained by schlieren photography should be processed with due consideration of several aspects:

- during the micro-explosion, droplets sometimes got on the video camera lens, thus introducing an additional error to the number of droplets in the frames. To eliminate this error, a mask was imposed on all the images. Static objects and impurities on the lens were masked with color, thus filling the masked domain in the images with zero signal (i.e. black).

- when conducting experiments with emulsions at high temperatures $\left(\geq 450{ }^{\circ} \mathrm{C}\right)$, a lot of smoke emerged after a droplet micro-explosion. This smoke also introduced an additional error by creating dark areas that the software identified as multiple small droplets or single large drops. The smoke could be removed from the images at the processing stage by imposing a mask on the image area occupied by smoke. This approach reduces the area, in which droplets can be found, thus decreasing their total number in the frames, but does not reduce the reliability of droplet size, as it would happen if we increased the binarization threshold.

The observational area for recording the micro-explosive fragmentation of heterogeneous droplets was $11.4 \times 11.4 \mathrm{~mm}$ in the case of both laser illumination (the field depth is about $0.5 \mathrm{~mm}$ ) and schlieren photography (the field depth is about $1.5 \mathrm{~mm}$ ). Thus, with the frame resolution of $612 \times 612$ pix, the systematic error in measuring the radii of child droplets $\left(R_{\mathrm{ch}-\mathrm{d}}\right)$ equals the half of scale factor, which was $0.01863 \mathrm{~mm}$. Thus, the systematic error approximated $0.0059 \mathrm{~mm}$.

Fig. 6 schematically represents the micro-explosive breakup of a droplet and shows the location of the observational area for tracking the emerging secondary fragments. The said location was chosen to minimize the interference caused by the re-reflected light sheet from the parent droplet and a high concentration of secondary fragments, i.e., before they left the light sheet plane. Micro-explosion is a three-dimensional process. Detecting droplets and recording their parameters in both cases (laser illumination and schlieren photography) were performed in a vertical section (Fig. 6) along the axis of symmetry of the primary droplet (within the field depth). It was assumed that the micro-explosive breakup of droplets is symmetrical in all vertical sections, the center of which passes along the axis of symmetry of the droplet. That is, the selected registration scheme provides a complete view of the process parameters and child droplet characteristics. Furthermore, a specific number of child droplets is used rather than their total number (section 4). This allows for a precise analysis of the experimental data obtained. 


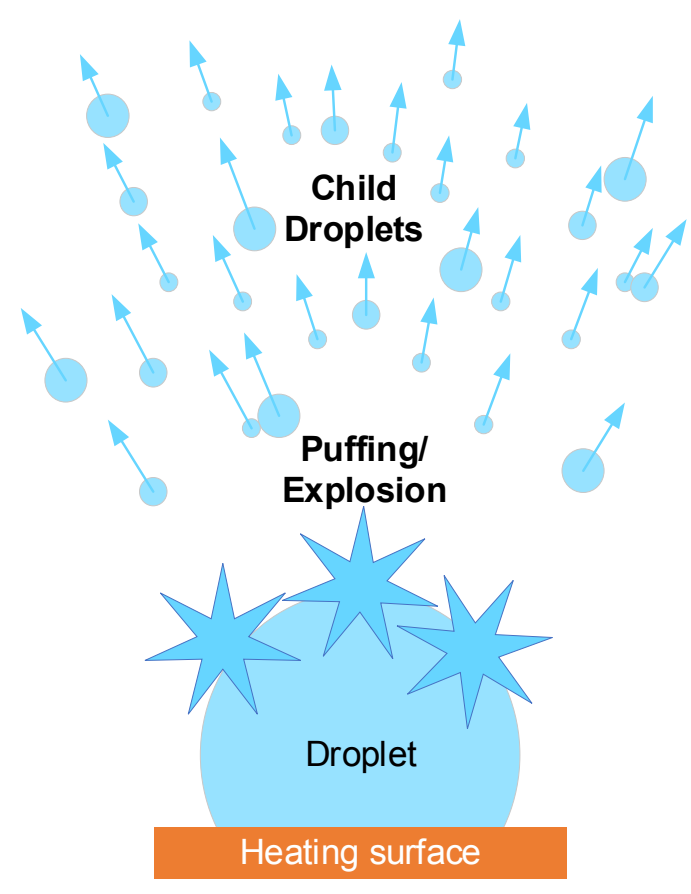

$a$

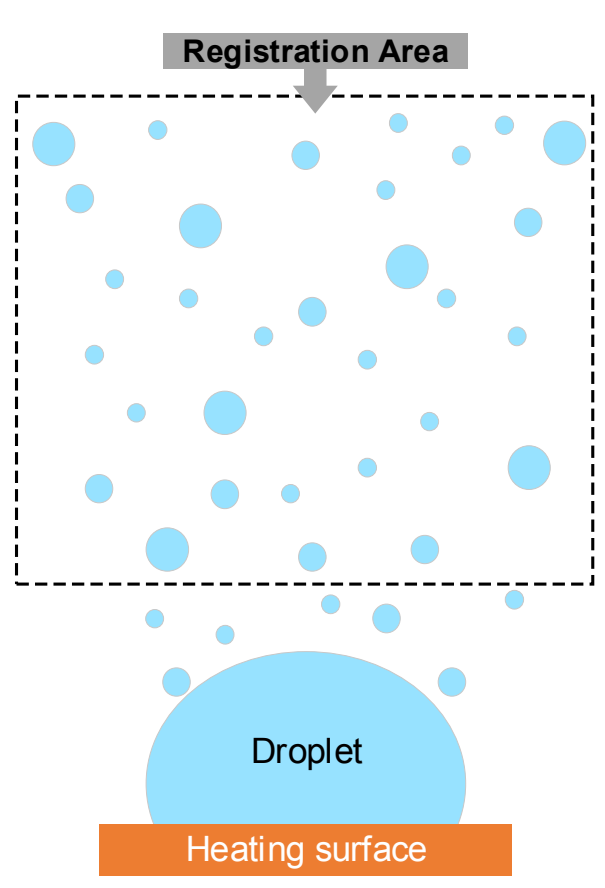

$b$

Fig. 6. $a$ - scheme of micro-explosive droplet breakup; $b$-observational area for determining the size, component composition, velocities, and trajectories of child droplets.

Calculating the velocities $\left(U_{\text {ch-d }}\right)$ of child droplets:

(i) at this stage, we used the video frames obtained with the help of laser illumination. We analyzed the images after their binarization (step 2 of data processing that were obtained using laser illumination);

(ii) in the resulting binarized image, we searched for separate child droplets (bright dots) and determined the location of particles. Then, using a dedicated algorithm, we determined the center of mass of each identified droplet and calculated its coordinates;

(iii) for each particle, we searched for a match within a certain radius in the next frame;

(iv) for matching particles, knowing the coordinates of the center of mass, we determined the distance the child droplets had covered for the time between the frames using PTV [19, 20]. After that, with the known scale factor and inter-frame delay, we calculated the velocity $\left(U_{\text {ch-d }}\right)$ of each droplet $(\mathrm{PTV}$ Algorithm);

(v) the time-average velocities $\left(U_{\text {ch-d }}\right)$ (components within the plane of sight) of child droplets were calculated for each heated surface temperature $\left(T_{\text {surf }}\right)$ (as an arithmetic mean of the velocities recorded for all the droplets). It is worth noting that the velocities are two-dimensional. However, since the vertical section, in which the velocities were calculated, is on the symmetry axis of the droplet, child droplets move almost exclusively in the selected plane. Thus, in this case the third component of the velocity is zero. For this reason, it was assumed that the calculated velocities were true. 
The PTV algorithm used in this research determines the coordinates of the droplet's center of mass to an accuracy of 1 pix. Thus, the maximum error in determining the velocity of child droplets $\left(U_{\text {ch- }}\right.$ d) is equivalent to 2 pix, which made up $0.1863 \mathrm{~m} / \mathrm{s}$ with a scale factor of $0.01863 \mathrm{~mm}$ and inter-frame delay of $0.0002 \mathrm{~s}$.

Using the findings of the series of experiments, we determined the component composition of child droplets. We also calculated the average kinetic energy of each droplet in each case: $E_{\mathrm{ch}-\mathrm{d}}=m_{\mathrm{ch}-\mathrm{d}} \cdot U_{\mathrm{ch}-}$

$\mathrm{d}^{2} / 2$. The average mass of a droplet was derived from the average droplet radius: $m_{\mathrm{ch}-\mathrm{d}}=4 / 3 \cdot \pi \cdot R_{\mathrm{ch}-\mathrm{d}}{ }^{3} \cdot \rho$. The average kinetic energy was determined only for micro-explosion. In puffing, the numerous droplets had a shape different from the spherical one due to their larger size. For this reason, it was impossible to accurately determine $m_{\text {ch-d }}$ and, consequently, accurately calculate $E_{\text {ch-d. }}$.

\section{Results and Discussion}

\subsection{Micro-explosion features}

The experiment illustrated the key aspects of micro-explosive fragmentation of heterogeneous droplets at different heating temperatures $\left(T_{\text {surf }}\right)$. However, even at the same heating temperature, the conditions of droplet heating and micro-explosive fragmentation were different. This stems from the joint influence of several factors. The main ones are the droplet component composition, the conditions of its contact with the heated surface, the heating temperature of the latter, and the location of the intercomponent interface. Below we describe the process under study in the Explosion regime for an immiscible two-component droplet ( 9 vol.\% of water) at different heating surface temperatures $\left(T_{\text {surf }}\right)$. The most typical conditions are outlined with different dynamic patterns of the secondary droplet generation and, hence, with different sizes, velocities, and trajectories (Figs. 7 and 8):

- $\left(250^{\circ} \mathrm{C}, \# 1\right)$ small droplets $\left(R_{\mathrm{ch}-\mathrm{d}}=0.02-0.15 \mathrm{~mm}\right)$ start breaking off from the parent droplet, which then breaks up into 2-4 large fragments followed by a micro-explosion;

- $\quad\left(250^{\circ} \mathrm{C}, \# 2\right)$ droplets with $R_{\mathrm{ch}-\mathrm{d}}=0.02-0.15 \mathrm{~mm}$ start breaking off from the droplet, a vertical jet is formed under the droplet (on the right), then the droplet breaks up into 10-20 large fragments (first stage) followed by the explosion of the rest of the droplet (second stage);

- $\left(300{ }^{\circ} \mathrm{C}, \# 1\right)$ the droplet somewhat grows in size, a "wormhole" (local micro-destruction of the surface) emerges in the upper left part of the droplet; 5-6 small droplets fly out of there; the droplet actively rolls around the substrate; as a result, 4-5 large fragments break off from it (first stage) followed by the explosion of the rest of the droplet (second stage);

- $\left(300^{\circ} \mathrm{C}\right.$, \#2) the droplet expands (grows in size by 3-4 times); several highly deformed areas ("wormholes") emerge in the upper left part of the droplet; within about $0.025 \mathrm{~s}$ several groups of small droplets, 5-15 droplets in each group, fly out of the wormholes; the droplet actively rolls around the substrate; as a result, 2-3 large fragments break off from it (first stage); a liquid jet 
emerges under the droplet (on the left) directed at about $45^{\circ}$; it breaks up into a group of secondary droplets followed by the micro-explosion of the rest of the droplet (second stage);

- $\left(350{ }^{\circ} \mathrm{C}, \# 1\right)$ the droplet expands gradually to increase in size by 3-4 times within $0.08-0.09 \mathrm{~s} ; 2-3$ large fragments and 15-20 small fragments break off from the left and upper parts (first stage), 56 medium-sized and large droplets break off from under the droplet (on the right); after that, the droplet jumps on the substrate; the rest of the droplet explodes when the droplet with a bubble inside it hits the substrate (second stage);

- $\left(350{ }^{\circ} \mathrm{C}, \# 2\right)$ nothing happens to the droplet within about $0.08 \mathrm{~s}$; then 5-6 small droplets break off from under the lower left part of the droplet; the droplet boils, jumps up on the substrate breaking into two almost equal parts and several dozens of small droplets break off from each part in various directions; both parts of the droplet fall on the substrate, where they micro-explode after $0.025 \mathrm{~s}$;

- $\left(400{ }^{\circ} \mathrm{C}, \# 1\right)$ nothing happens to the droplet within about $0.1-0.11 \mathrm{~s}$; then it expands significantly to increase in size by 2-3 times within $0.02 \mathrm{~s}$; in the process, several dozens of small droplets break off in all directions; then an explosion occurs in the upper part of the droplet followed by the droplet breaking up into two large fragments and multiple small fragments;

- $\left(400{ }^{\circ} \mathrm{C}, \# 2\right)$ the droplet rolls around the substrate for about $0.065 \mathrm{~s}$ and then it expands significantly to increase in size by $2-3$ times within about $0.015 \mathrm{~s}$; the droplet jumps up a bit on the substrate and then lands; several small droplets break off from it and it becomes almost as small as it was originally; an explosion occurs in the upper part of the droplet; as a result, 2-3 large fragments and many small fragments break off from it; the droplet moves actively; one large fragment breaks off from it; the second explosion occurs in the lower part and as a result one large fragment and multiple small fragments break off; the droplet moves (rolls and jumps up a bit) around the substrate; its micro-explosive breakup occurs;

- $\left(450{ }^{\circ} \mathrm{C}, \# 1\right)$ the droplet rolls around the substrate for about $0.085 \mathrm{~s}$ and then expands significantly to increase in size by 2-3 times within about $0.015 \mathrm{~s}$; the droplet boils and several small fragments break off from it in the process; about $0.2 \mathrm{~s}$ after the droplet discharge, it becomes almost as small as it was originally; the droplet deforms rapidly (boils); a micro-explosion occurs in the lower part of the droplet; the droplet breaks up into 2-3 large fragments and multiple small fragments;

- $\left(450{ }^{\circ} \mathrm{C}, \# 2\right)$ the droplet rolls around the substrate for about $0.075 \mathrm{~s}$ and then expands rapidly to increase in size by 2-3 times within about $0.08 \mathrm{~s}$; an explosion occurs in the lower left part of the droplet resulting in two large fragments breaking off from it; the droplet boils; the second local explosion occurs in the lower left part of the droplet resulting in 10-15 small fragments breaking off from it; $0.18 \mathrm{~s}$ after the droplet discharge, an explosion occurs in its lower part; the droplet breaks up into multiple small fragments; 
- $\left(500^{\circ} \mathrm{C}, \# 1\right)$ the droplet rolls around the substrate for about $0.1 \mathrm{~s}$ and then expands significantly to increase in size by 2-3 times within about $0.025 \mathrm{~s}$; the droplet boils and gradually shrinks down to its original size within about $0.11 \mathrm{~s}$; several fragments break off from the droplet; the droplet moves around the substrate; an explosion occurs in the lower left part of the droplet to form many small fragments; the main part of the droplet falls from the heated substrate almost without atomization;

- $\quad\left(500{ }^{\circ} \mathrm{C}, \# 2\right)$ the droplet rolls around the substrate for about $0.08 \mathrm{~s}$ and then expands significantly to increase in size by $2-3$ times within about $0.017 \mathrm{~s}$; the droplet boils and gradually shrinks down to its original size within about $0.12 \mathrm{~s}$; a local explosion occurs in the upper right part of the droplet; several small fragments break off from the droplet; the droplet jumps up on the substrate and the second local explosion occurs when it lands; the droplet jumps up on the substrate the second time and rolls for some time after landing; after that, an explosion occurs in the lower part of the droplet and the droplet breaks up into two large fragments and multiple small fragments;

- $\left(550^{\circ} \mathrm{C}, \# 1\right)$ the droplet rolls around the substrate for about $0.12 \mathrm{~s}$ and then expands significantly to increase in size by $2-3$ times within about $0.018 \mathrm{~s}$; the droplet boils and gradually shrinks down to its original size within $0.1 \mathrm{~s}$; the droplet goes on rolling around the substrate; an explosion occurs in the lower part of the droplet $0.36 \mathrm{~s}$ after the droplet was placed on the substrate; the droplet breaks up into multiple small fragments;

- $\left(550^{\circ} \mathrm{C}, \# 2\right)$ the droplet rolls around the substrate for about $0.12 \mathrm{~s}$ and then expands significantly to increase in size by 2-3 times within about $0.025 \mathrm{~s}$; the droplet boils and gradually shrinks down to its original size within $0.09 \mathrm{~s}$; the droplet goes on rolling around the substrate; an explosion occurs in the lower part of the droplet $0.45 \mathrm{~s}$ after the droplet was placed on the substrate; the droplet breaks up into multiple small fragments;

- $\left(550^{\circ} \mathrm{C}, \# 3\right)$ the droplet rolls around the substrate for about $0.21 \mathrm{~s}$ (one small fragment breaks off from it during that time); then an explosion occurs in the lower part of the droplet and the droplet breaks up into multiple small fragments.

Thus, when heated, the droplets increase in size almost identically at the first stage, irrespective of the heating rate variation. Then the droplet shrinks and starts to break up into fragments. This process ends up with an intense micro-explosion generating a cloud of small fragments.

We have analyzed the video frames of the experiments to produce summary tables and highlight the key aspects of the process under study for immiscible two-component droplets and emulsion droplets (Tables 2 and 3). Several types of the Explosion regimes are singled out that we observed in the experiments with immiscible two-component droplets (Table 2). However, when it comes to the emulsion droplets, the process is relatively stable (Table 3). When heated, these droplets (unlike the immiscible 
ones) rarely showed an increase in size, local micro-explosions, or large $\left(R_{\text {ch-d }}=0.15-0.4 \mathrm{~mm}\right)$ and small $\left(R_{\mathrm{ch}-\mathrm{d}}=0.02-0.15 \mathrm{~mm}\right)$ secondary fragments breaking off from them (Tables 2,3$)$.

Table 2. Key parameters of micro-explosive breakup of immiscible two-component droplets (with varying $T_{\text {surf). }}$.

\begin{tabular}{|c|c|c|c|c|c|c|c|c|c|c|c|c|c|c|c|}
\hline \multirow{3}{*}{ Parameter } & \multicolumn{15}{|c|}{ Temperature $T_{\text {surf }}\left({ }^{\circ} \mathrm{C}\right)$} \\
\hline & \multicolumn{2}{|c|}{250} & \multicolumn{2}{|c|}{300} & \multicolumn{2}{|c|}{350} & \multicolumn{2}{|c|}{400} & \multicolumn{2}{|c|}{450} & \multicolumn{2}{|c|}{500} & \multicolumn{3}{|c|}{550} \\
\hline & $\# 1$ & $\# 2$ & $\# 1$ & $\# 2$ & $\# 1$ & $\# 2$ & $\# 1$ & $\# 2$ & $\# 1$ & $\# 2$ & $\# 1$ & $\# 2$ & $\# 1$ & $\# 2$ & $\# 3$ \\
\hline $\begin{array}{l}\text { Droplets with } R_{\text {ch-d }}=0.02- \\
0.15 \mathrm{~mm} \text { breaking off when } \\
\text { heated }\end{array}$ & $\mathrm{x}$ & $\mathrm{X}$ & $\mathrm{x}$ & $x$ & $\mathrm{x}$ & $x$ & $x$ & $\mathrm{X}$ & $\mathrm{X}$ & & & & & & \\
\hline $\begin{array}{l}\text { Droplets with } R_{\mathrm{ch}-\mathrm{d}}=0.15- \\
0.4 \mathrm{~mm} \text { breaking off when } \\
\text { heated }\end{array}$ & $\mathrm{X}$ & $x$ & $\mathrm{X}$ & $\mathrm{X}$ & $\mathrm{x}$ & $\mathrm{X}$ & & $\mathrm{X}$ & & & & & & & \\
\hline $\begin{array}{l}\text { Local explosions in the lower } \\
\text { part }\end{array}$ & & $\mathrm{x}$ & & $\mathrm{X}$ & $\mathrm{x}$ & $x$ & & $\mathrm{x}$ & & $\mathrm{x}$ & & & & & \\
\hline $\begin{array}{l}\text { Local explosions in the } \\
\text { lateral/upper part }\end{array}$ & & & $\mathrm{X}$ & $x$ & & & $x$ & $x$ & & & & $x$ & & & \\
\hline Increase in the droplet volume & & & & $\mathrm{x}$ & $\mathrm{x}$ & $\mathrm{x}$ & $\mathrm{x}$ & $\mathrm{x}$ & $\mathrm{x}$ & $\mathrm{x}$ & $\mathrm{x}$ & $\mathrm{x}$ & $\mathrm{x}$ & $\mathrm{x}$ & \\
\hline $\begin{array}{l}\text { Droplet rolling around the } \\
\text { substrate }\end{array}$ & & & & & & & & $x$ & $x$ & $x$ & $x$ & $x$ & $\mathrm{x}$ & $x$ & $\mathrm{x}$ \\
\hline Droplet jumping & & & & & $\mathrm{x}$ & $\mathrm{X}$ & & $\mathrm{X}$ & & & & $\mathrm{x}$ & & & \\
\hline
\end{tabular}

Table 3. Key parameters of micro-explosive breakup of emulsion droplets (with varying $T_{\text {surf }}$ ).

\begin{tabular}{|l|l|l|l|l|l|l|l|l|l|}
\hline \multirow{2}{*}{\multicolumn{1}{|c|}{ Parameter }} & \multicolumn{7}{|c|}{ Temperature $T_{\text {surf }}\left({ }^{\circ} \mathrm{C}\right)$} \\
\cline { 2 - 10 } & \multicolumn{2}{|c|}{400} & \multicolumn{2}{|c|}{450} & \multicolumn{2}{|c|}{500} & \multicolumn{2}{|c|}{550} \\
\cline { 2 - 10 } & $\# 1$ & $\# 2$ & $\# 1$ & $\# 2$ & $\# 1$ & $\# 2$ & $\# 1$ & $\# 2$ \\
\hline $\begin{array}{l}\text { Small droplets breaking off } \\
\text { under heating }\end{array}$ & & & $\mathrm{x}$ & $\mathrm{x}$ & & & & \\
\hline $\begin{array}{l}\text { Droplet rolling around the } \\
\text { substrate }\end{array}$ & $\mathrm{x}$ & $\mathrm{x}$ & & $\mathrm{x}$ & $\mathrm{x}$ & $\mathrm{x}$ & $\mathrm{x}$ & $\mathrm{x}$ \\
\hline Droplet jumping & & $\mathrm{x}$ & & $\mathrm{x}$ & & & & \\
\hline
\end{tabular}

When heated, emulsion droplets remain stable for a longer time than immiscible two-component droplets do largely due to the component distribution in the parent droplet [14]. Thus, in an emulsion droplet, water is evenly distributed throughout the droplet at the reference time. Liquid circulates continuously within the droplet being heated. Due to the small size of the micro-droplets of water (less than $1 \mu \mathrm{m})$, they are entrained by the convective flows. Stable circulation of micro-droplets leads to their more even heating. Micro-droplets coalesce into larger fragments, which then leads to the microexplosive breakup [14]. An increase in the temperature of the heating surface intensifies the convection in the droplet, accelerates the circulation flows and leads to larger-sized vortices. As a result, heating and 
micro-explosive breakup are accelerated, while the nature of the processes within the droplet remains unaffected (Table 3).

In the case of immiscible two-component droplets, the heating process followed by the microexplosive breakup differs (Table 2) depending on the temperature of the heating surface (see three typical cases of Explosion in Fig. 7). This happens due to the highly heterogeneous structure of the parent droplet. At the reference time, a tetradecane droplet only contains one large fragment of water. The density of water $(0.997 \mathrm{~g} / \mathrm{mL})$ is greater than that of tetradecane $(0.762 \mathrm{~g} / \mathrm{mL})$, so the water component is at the bottom of the droplet, in the immediate vicinity of the substrate. However, when the parent droplet is placed on the substrate, the water component may be located either in the center or (most frequently) near the side surface of the parent droplet. Moreover, internal current velocities in the parent droplets are not enough to break up a monolithic water component into small droplets. As a rule, it breaks up into 2-3 large fragments and up to 10-15 smaller ones. These factors lead to the superheating and boiling of the large water fragment and thus we can see the following (see Table 2): droplets with $R_{\text {ch-d }}=0.02-0.15 \mathrm{~mm}$ breaking off when heated; droplets with $R_{\text {ch-d }}=0.15-0.4 \mathrm{~mm}$ breaking off when heated; local explosions in the lower part; local explosions in the lateral/upper part. At $T_{\text {surf }}=350-400{ }^{\circ} \mathrm{C}$, water-in-diesel drops reach the Leidenfrost point $\left(350^{\circ} \mathrm{C}\right)[14]$, and the droplet starts rolling around the substrate (Table 2). This intensifies the breakup of the initial water component into smaller droplets, makes their heating more even and, as a result, reduces the number of local explosions and separate fragments breaking off. At $T_{\text {surf }}>450^{\circ} \mathrm{C}$, the internal current velocities in a droplet are intensified, causing the water component to break up into micro-droplets due to high temperatures of the heating surface. The water component distributes evenly throughout the parent droplet to form emulsion. This leads to similar characteristics of micro-explosive breakup for an immiscible two-component droplet and an emulsion droplet.

Fig. 7 presents the video frames showing the three typical cases of Explosion (as exemplified by an immiscible two-component droplet). In the first case (Fig. 7a), we observe a relatively stable location of the droplet without any significant movement around the substrate. At the same time, we recorded small $\left(R_{\mathrm{ch}-\mathrm{d}}=0.02-0.15 \mathrm{~mm}\right)$ and large $\left(R_{\mathrm{ch}-\mathrm{d}}=0.15-0.4 \mathrm{~mm}\right)$ droplets breaking off throughout the heating process; local micro-explosions were frequent, resulting in liquid jets and droplets breaking off from the droplet and moving at high velocities. Overall, the micro-explosion parameters in this regime are close to the similar conditions for the Puffing regime: the size of newly formed droplets is usually $R_{\mathrm{ch}-\mathrm{d}}=0.06-0.21$ $\mathrm{mm}$. The case in point was often observed at $T_{\text {surf }}=250-350{ }^{\circ} \mathrm{C}$. In the second case (Fig. $7 b$ ), we can see the droplet moving around the substrate as well as a slight increase in the droplet volume (by 1.2-1.5 times). Under heating, large fragments with a radius of up to $0.4-0.6 \mathrm{~mm}$ broke off from the main droplet. The micro-explosive breakup was rather intense in this case. The case in point was often observed when $T_{\text {surf }}=300-400{ }^{\circ} \mathrm{C}$. In the third case (Fig. $7 \mathrm{c}$ ), the droplet was actively moving around the substrate. About 0.06-0.11 s after the droplet placement, its size increased significantly (by $2-4$ times), the droplet started 
boiling, and about $0.18-0.21 \mathrm{~s}$ after the droplet placement on the substrate, it shrank almost to the original size. A short-term droplet heating was followed by its micro-explosive breakup. The case in point was usually recorded at the substrate temperatures $T_{\text {surf }}=450-550{ }^{\circ} \mathrm{C}$. Further we present the findings predominantly for the third case, since it involved the formation of a fine mist aerosol, which can improve the efficiency of fuel droplet evaporation and combustion.
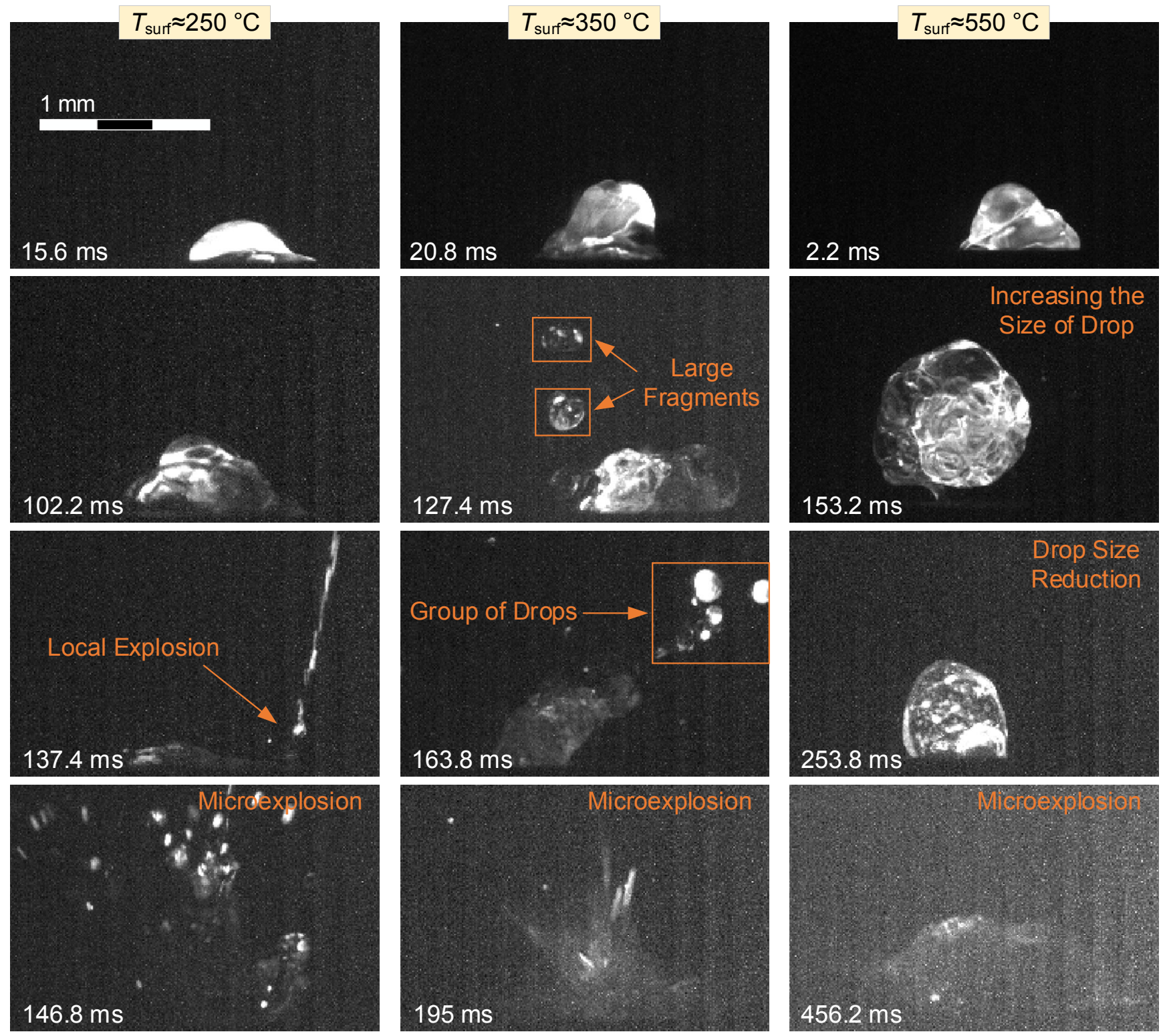

$a$

$b$

$c$

Fig. 7. Video frames showing the three $(a-c)$ typical cases of Explosion (as exemplified by an immiscible two-component droplet).

As an example, Fig. 8 shows video frames illustrating the typical trajectories of child droplets produced from a micro-explosion. According to the analysis of the experiments, child droplets fly off from the initial droplet in the radial direction. Fig. 8 indicates that the aerosol cloud of secondary droplets almost evenly increases in size in all the directions relative to the area of contact with the heated substrate. At the same time, it can be seen (Fig. 8) that child droplets cover a distance of about $6 \mathrm{~mm}$ 
within less than $5 \mathrm{~ms}$ after the micro-explosion. This result is important for predicting the parameters of the formation of such aerosol clouds in actual combustion chambers during the micro-explosive breakup of droplets, both through contact with heated walls and when moving along these walls. The said processes involved in the secondary atomization may be the reason why a fine fuel aerosol uniformly fills the internal volume of the chamber. The trajectories of the secondary droplets will intersect. These processes will intensify the additional atomization of fuel droplets in the combustion chamber. As a result, given the flight trajectories of the secondary droplets, we can predict their combined atomization through the micro-explosion as well as collisions with each other and with heated walls of the combustion chambers. These conditions are generally regarded as having a high potential for fuel technologies, since they increase the reaction area of fuel by dozens of times [35].
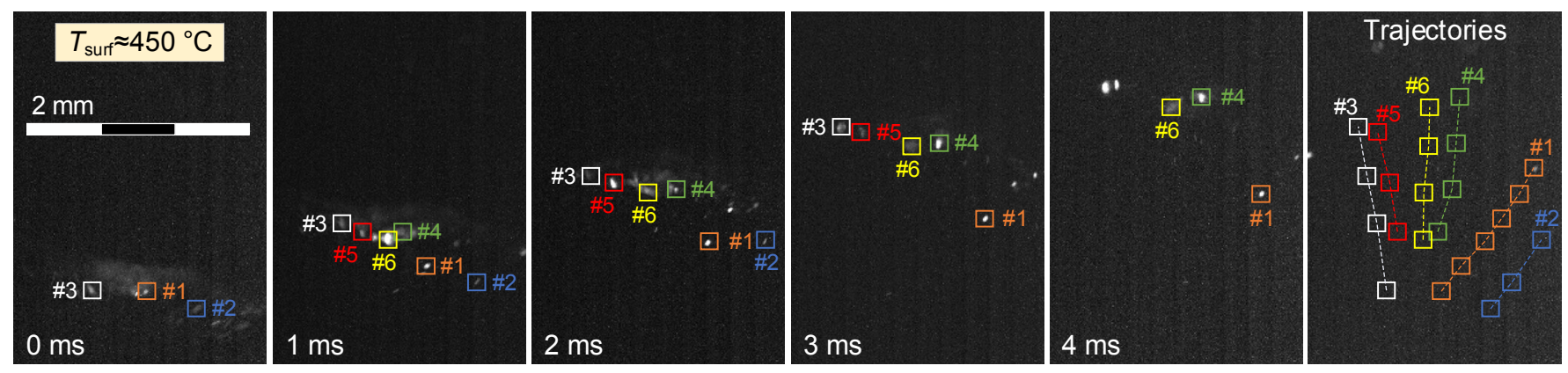

Fig. 8. Video frames showing a typical trajectory of child droplets produced from the micro-explosion of the initial immiscible two-component droplet (\#1-6 are the numbers of child droplets).

\subsection{Child droplet temperatures}

Figs. 9 and 10 show the temperatures of child droplets derived from the experimental findings. The temperatures are shown in Area\#1, Area\#2, Area\#3, as well as in Complete Area (Fig. 3). The temperature of secondary fragments does not only depend on the temperature of the heated surface but also on the distance covered relative to the micro-explosion boundary as well as on the sizes and velocities. Unsurprisingly, the higher the substrate surface temperature, the higher the temperature of secondary fragments. Moreover, when the temperature of the substrate reaches $500{ }^{\circ} \mathrm{C}$, the temperature of secondary droplets increases by as little as several degrees. This result can be considered crucial for practical applications, because it shows that reaching threshold (critical) temperatures is enough for the production of a high-temperature fine mist. The result obtained stems from the high heat capacity and vaporization heat of water. Thus, even high-temperature heating cannot change the $T_{\text {ch-d }}$ significantly because the phase change temperature of oil is constant at atmospheric pressure and the parent drop temperature stays more or less constant.

Figs. 9 and 10 suggest that the temperatures of secondary fragments resulting from microexplosion and puffing are rather close: they only differ by several degrees, which is within the 
measurement error when optical techniques are used. A possible reason for this result is that fragments break off from the droplet in the puffing regime much less frequently than during a micro-explosion. Another point is that the child droplets generated in the puffing regime are larger than those resulting from a micro-explosion. Therefore, despite the smaller number of child droplets in the puffing regime, their average temperature corresponds to the average temperature of a much larger number of secondary droplets in the micro-explosion regime. This result also indicates that micro-explosion is not the only promising regime of the secondary atomization of fuel droplets: puffing also has high potential.
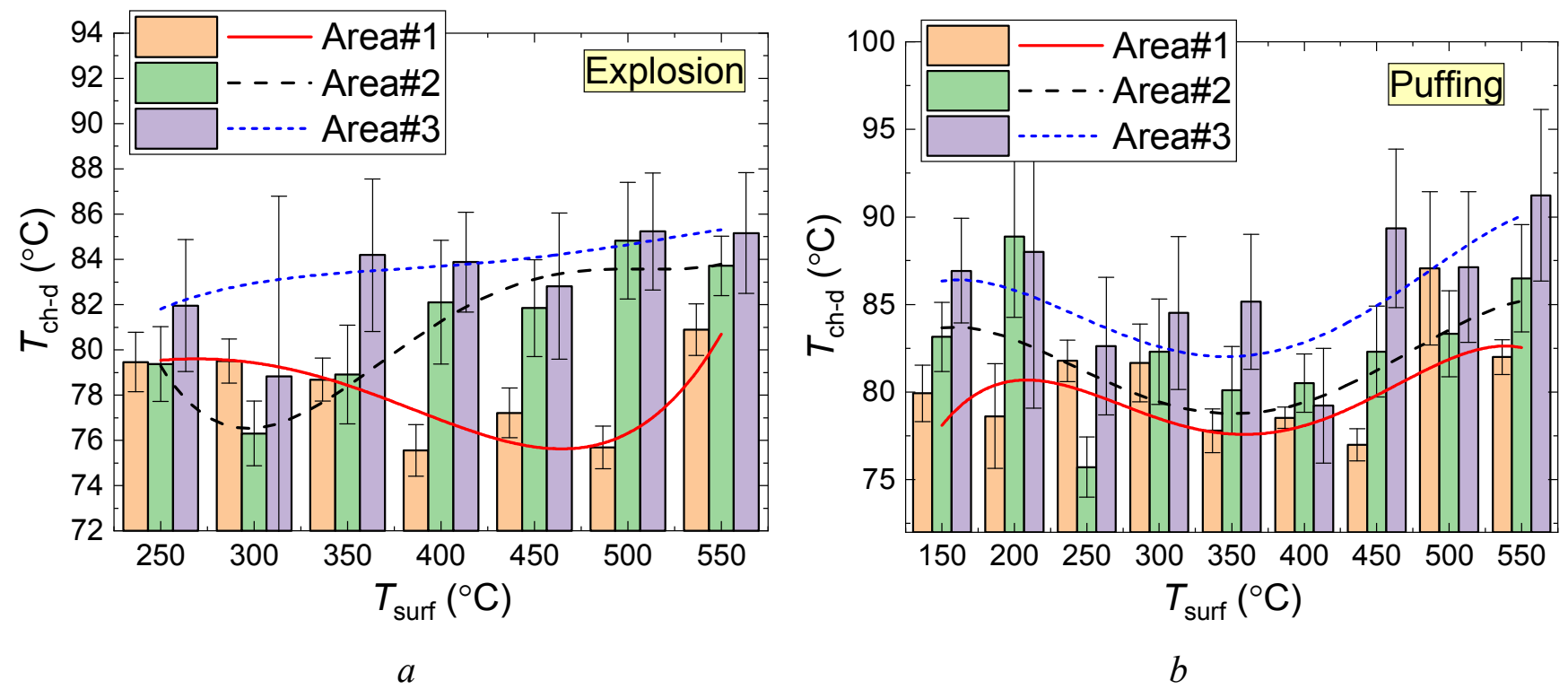

Fig. 9. Temperatures of child droplets in Area\#1, Area\#2, and Area\#3 for an immiscible two-component droplet with varying surface temperature $\left(T_{\text {surf }}\right)$ in the Explosion $(a)$ and Puffing $(b)$ regimes.

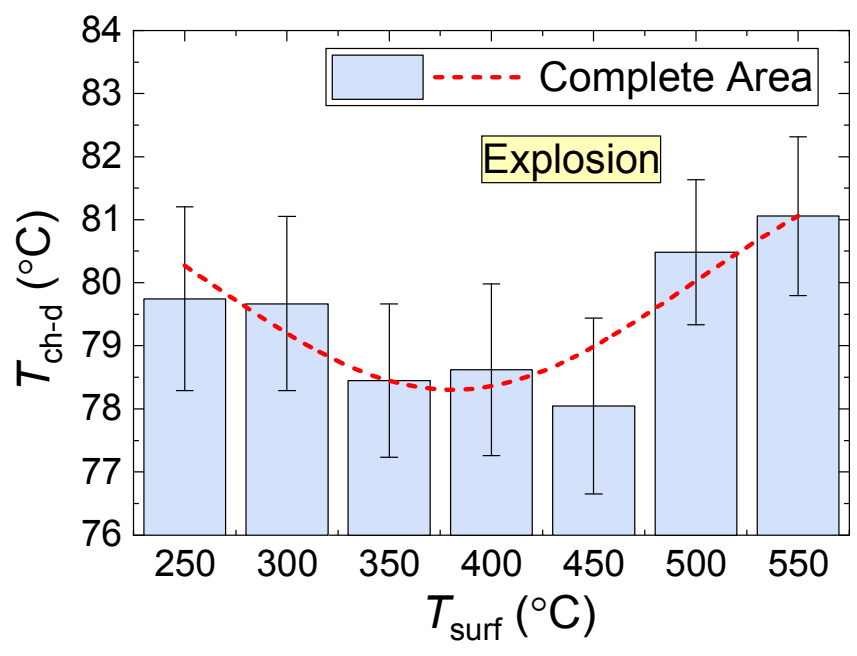

$a$

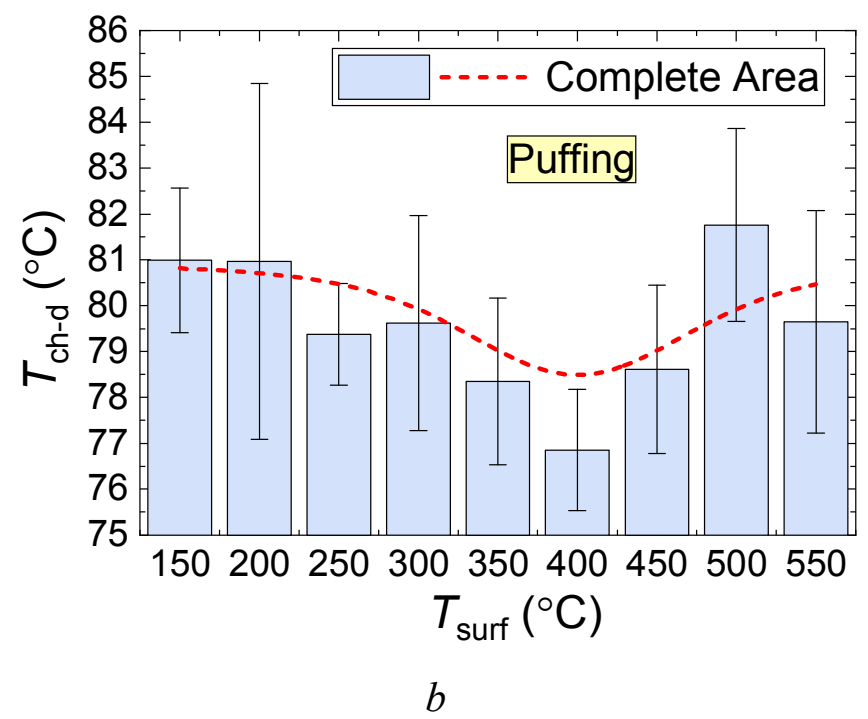

Fig. 10. Average temperatures of child droplets (Complete Area) of an immiscible two-component droplet with varying surface temperature $\left(T_{\text {surf }}\right)$ for the Explosion $(a)$ and Puffing $(b)$ regimes. 
If we compare the location of the initial droplet on the substrate and the temperatures of the secondary fragments in the three highlighted areas (Fig. 9), we can see that the longer the contact of the initial droplet with the substrate, the higher the temperature of secondary fragments in all the observational areas, especially in the first one. The temperatures of secondary fragments in the second and third areas are predominantly affected by their size and velocity. The higher the velocity and the smaller the size, the higher the temperature $T_{\text {ch-d }}$. Since micro-explosion was the prevalent regime at above $350{ }^{\circ} \mathrm{C}$, the size and velocity of child droplets did not change much with an increase in $T_{\text {surf }}$ and hence the values of $T_{\text {ch-d }}$ were also almost identical in the range of $T_{\text {surf }}=350-550{ }^{\circ} \mathrm{C}$. The puffing regime generated fewer secondary droplets, their size was larger and their velocities were lower as compared to micro-explosion. That is why the values of $T_{\text {ch-d }}$ were lower at $T_{\text {surf }}<350{ }^{\circ} \mathrm{C}$.

According to the experimental findings (Fig. 9), as the child droplets move away from the parent droplet (and the substrate), their temperature increases on average by $4-6{ }^{\circ} \mathrm{C}$. This result apparently stems from the child droplets being heated by the convective heat fluxes ascending from the metal substrate. The established result is of great scientific interest, because it shows that the emerging secondary droplets are heated rather actively despite the several-fold increase in the evaporation rate as compared to the initial droplets. Therefore, we can conclude that the energy spent on the micro-explosion of the initial droplet will be compensated for by a much greater heat release in the chamber when a heated cloud of secondary fragments is generated. In addition, heated secondary droplets may serve as sources of additional heating for fuel droplets in a combustion chamber, i.e., large adjacent droplets will receive extra heating and their micro-explosive breakup will be intensified. These results show high probability of the chain-like distribution of micro-explosive effects in combustion chambers. Moreover, at each subsequent stage, the temperature and velocity of secondary droplets will be higher and their size smaller. That is why we can predict the formation of a high-temperature fine aerosol cloud.

Fig. 11 shows the lifetime of immiscible two-component droplets versus the temperature of the heated surface. The patterns of the location of experimental points in Figs. 10 and 11 clearly correlate with each other. That is, an increase in the temperature of child droplets can be explained by the shorter lifetime of parent droplets, i.e., shorter duration of their heating when they are in contact with a solid surface. As a result, child droplets did not have enough time to reach higher temperatures. The findings presented in Figs. 10 and 11 show some possible mechanisms of managing the Explosion/Puffing delay times. We can also see that the $t_{\mathrm{e}}\left(T_{\text {surf }}\right)$ function is highly nonlinear. This illustrates a pronounced extremum in the temperature range from 350 to $400{ }^{\circ} \mathrm{C}$. At lower temperatures, droplets rather actively spread over the heated surface, were heated throughout their volume and evaporated. However, the high heat capacity and vaporization heat of water led to a significant increase in the heating time until microexplosion. At $T_{\text {surf }}>400{ }^{\circ} \mathrm{C}$, the contact of the initial droplet with the substrate was usually accompanied by bouncing, boiling, and surface transformation. Under such conditions, only a thin near-surface layer 
was heated extensively. That is why the parent droplet needed more time for heating until microexplosion. In the temperature range $T_{\text {surf }}=350-400{ }^{\circ} \mathrm{C}$, the droplet remained on the heated surface while retaining its hemispherical shape. This contributed to its fast heating and minimum $t_{\mathrm{e}}$.

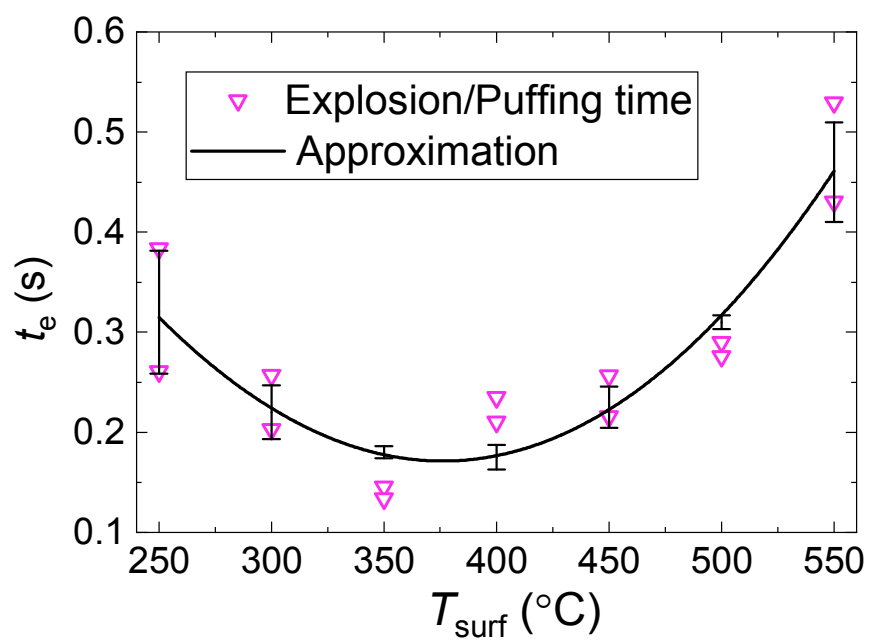

Fig. 11. Explosion/Puffing delay times $\left(t_{\mathrm{e}}\right)$ of the parent immiscible two-component droplet with varying surface temperature $\left(T_{\text {surf }}\right)$.

\subsection{Child droplet sizes}

The micro-explosive fragmentation of heterogeneous liquid droplets took different times. This parameter largely depended on the type of droplet (emulsion or immiscible two-component droplet) and on the temperature of the heated surface $T_{\text {surf. Therefore, to generalize the results obtained, we calculated }}$ the specific number $\left(N_{\text {pf }}\right)$, average number $(n)$, average radius $\left(R_{\text {ch-d }}\right)$, and total volume $\left(V_{\text {sum }}\right)$ of the child droplets generated throughout the micro-explosive fragmentation. Further we give the main findings of our experiments (Figs. 12-16) and the calculation algorithms for the key parameters.

Figs. 12 and 13 show the average child droplet size distributions obtained from the analysis of 3 to 5 experiments in each of the series. The parameter $N_{\mathrm{pf}}$ denotes the average number of droplets of each size in one frame. For each $R_{\mathrm{ch}-\mathrm{d}}$, the parameter is given by:

$$
N_{\mathrm{pf}}=\left(N_{\mathrm{pf}(1)}+N_{\mathrm{pf}(2)}+\ldots+N_{\mathrm{pf}(\mathrm{m})}\right) / m=\left(N_{1} / k_{1}+N_{2} / k_{2}+\ldots+N_{\mathrm{m}} / k_{\mathrm{m}}\right) / m .
$$
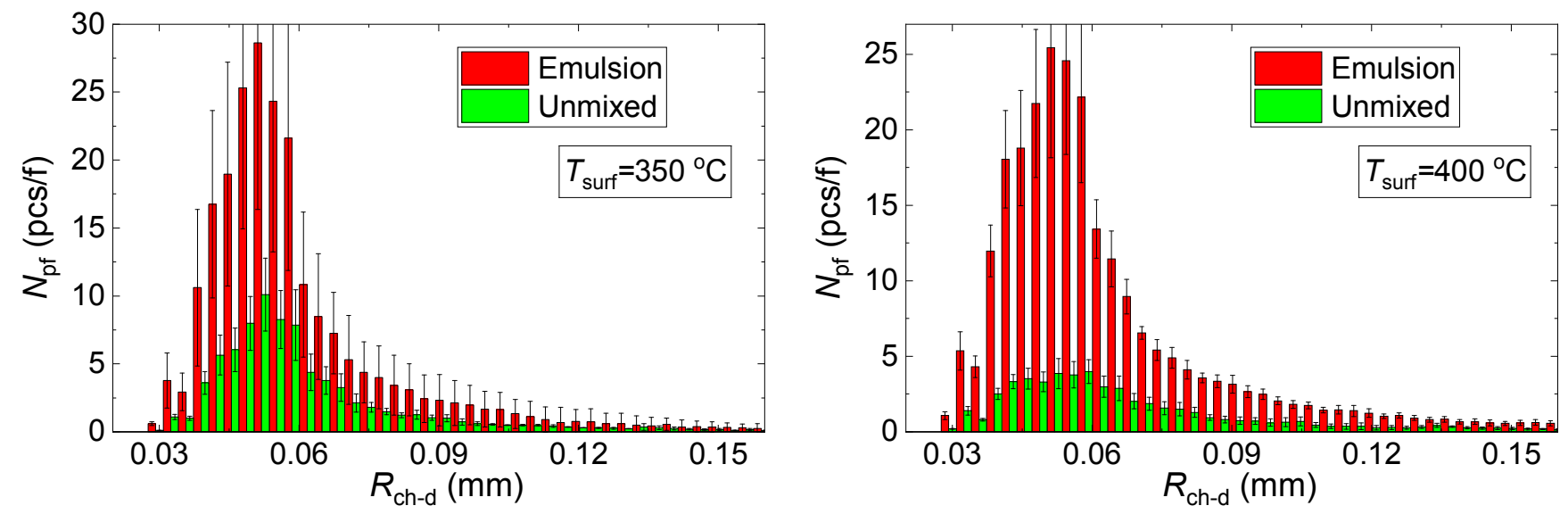

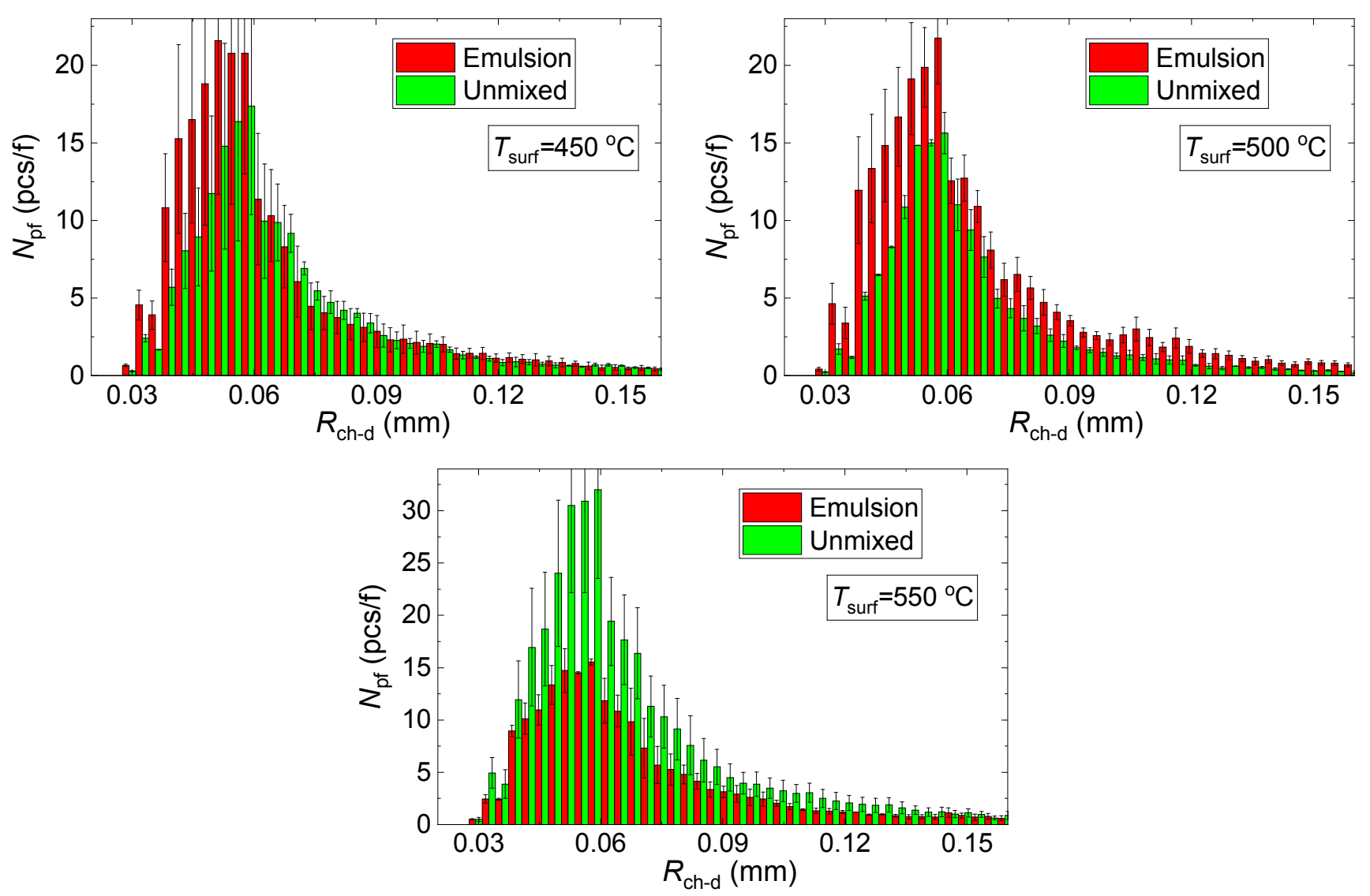

Fig. 12. Size distributions of child droplets produced from the micro-explosion of emulsion droplets and immiscible two-component droplets with varying temperature $\left(T_{\text {surf }}=350-550{ }^{\circ} \mathrm{C}\right)$ obtained using schlieren photography.

At first we intended to use the parameter $N=\left(N_{1}+N_{2}+\ldots+N_{\mathrm{m}}\right) / m$ (absolute average number of

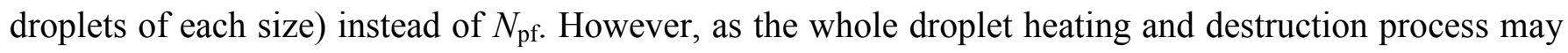
take different time and since the power of the micro-explosion (its duration and rate) may differ from one experiment to another and take different time, the number of droplets analyzed in separate experiments could differ, all other things being equal. Therefore, it was incorrect to compare separate experiments at identical $T_{\text {surf }}$ or different temperatures. That is why we decided to use the average number of droplets of each size per frame $\left(N_{\mathrm{pf}}\right)$.

We have drawn several conclusions from the analysis of the results obtained. Key comments on the results of schlieren photography (Fig. 12):

- for emulsion droplets, the micro-explosion is overall rather stable. The duration and manner of the process do not change much with an increase in the temperature $T_{\text {surf }}$, hence the peak values of $N_{\text {pf }}$ differ negligibly in Fig. 12. There is a slight decrease in $N_{\text {pf }}$ at $T_{\text {surf }} \approx 550{ }^{\circ} \mathrm{C}$. At high temperatures, a part of water and tetradecane evaporates, which reduces $N_{\text {pf; }}$;

- with immiscible two-component droplets (described earlier), we often observe the first and second cases of the Explosion regime at the temperatures $T_{\text {surf }}$ of up to $400{ }^{\circ} \mathrm{C}$. In these cases, rather large 
fragments (with a radius of up to $0.6 \mathrm{~mm}$ ) may break off from the droplet (Fig. 7). Thus, by the time of explosive breakup, the droplet volume may decrease significantly, which reduces $N_{\mathrm{pf}}$ at $T_{\text {surf }}=350{ }^{\circ} \mathrm{C}$ and $T_{\text {surf }}=400{ }^{\circ} \mathrm{C}$. The values of $N_{\text {pf }}$ at $T_{\text {surf }}=450-500{ }^{\circ} \mathrm{C}$ are stable because the processes are similar (local micro-explosions with small fragments breaking off); moreover, at these temperatures we mostly observe the third case of Explosion. At $T_{\text {surf }}=550{ }^{\circ} \mathrm{C}, N_{\mathrm{pf}}$ increases by 1.5-2 times because almost no fragments or micro-droplets break off from the droplet being heated (Table 2). That is why the droplet retains almost all of its original volume by the moment of micro-explosion, which leads to a significant increase in $N_{\mathrm{pf}}$.

The results of laser illumination (Fig. 13) show a common trend for both immiscible and emulsion droplets. In that case only water is detected by the camera (because the fluorophore is only soluble in water). In particular, Fig. 13 demonstrates that the maximum value of $N_{\text {pf }}$ goes down with an increase in

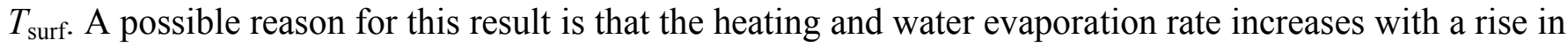
the surface temperature ( $T_{\text {surf }}$ ), so water evaporates faster. As a result, the number of water droplets gradually decreases (with a rise in $T_{\text {surf }}$ ) during the micro-explosion.
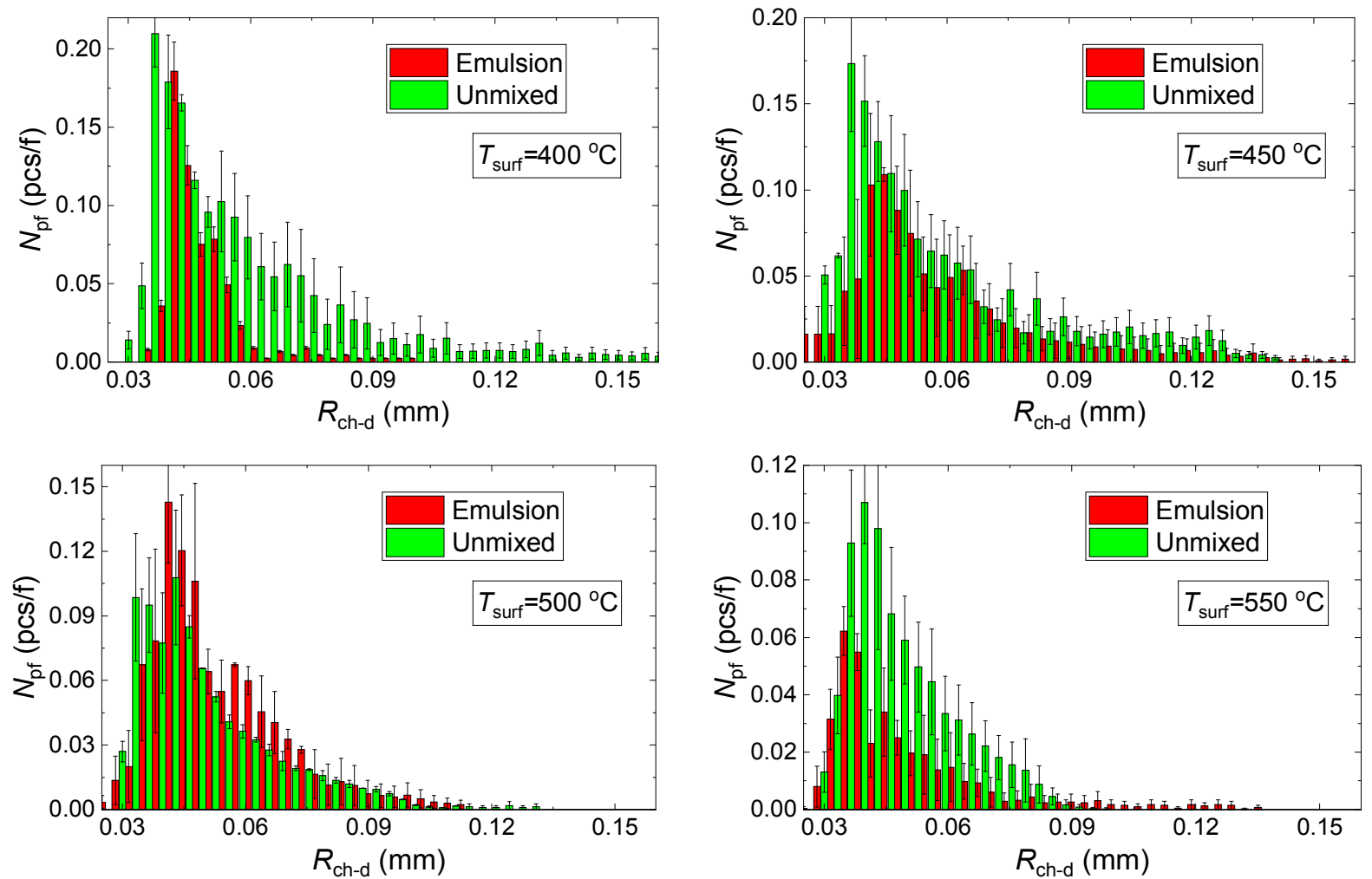

Fig. 13. Size distributions of child droplets produced from the micro-explosion of emulsion droplets and immiscible two-component droplets with varying temperature $\left(T_{\text {surf }}=400-550^{\circ} \mathrm{C}\right)$ obtained using laser illumination.

To generalize the data given in Figs. 12 and 13, we calculated the average radii $\left(R_{\text {ch-d }}\right)$ and number $(n)$ of child droplets per frame for schlieren photography and laser illumination (Figs. 14 and 15):

$$
R_{\text {ch-d }}=\left(R_{\text {ch-d(1) }} \cdot N_{\text {pf }(1)}+R_{\text {ch-d }(2)} \cdot N_{\text {pf( } 2)}+\ldots+R_{\text {ch-d(i) }} \cdot N_{\text {pf(i) })} /\left(N_{\text {pf }(1)}+N_{\text {pf( }(2)}+\ldots+N_{\text {pf(i) }}\right),\right.
$$




$$
n=\left(N_{\mathrm{pf}(1)}+N_{\mathrm{pf}(2)}+\ldots+N_{\mathrm{pf}(\mathrm{i})}\right) / i
$$
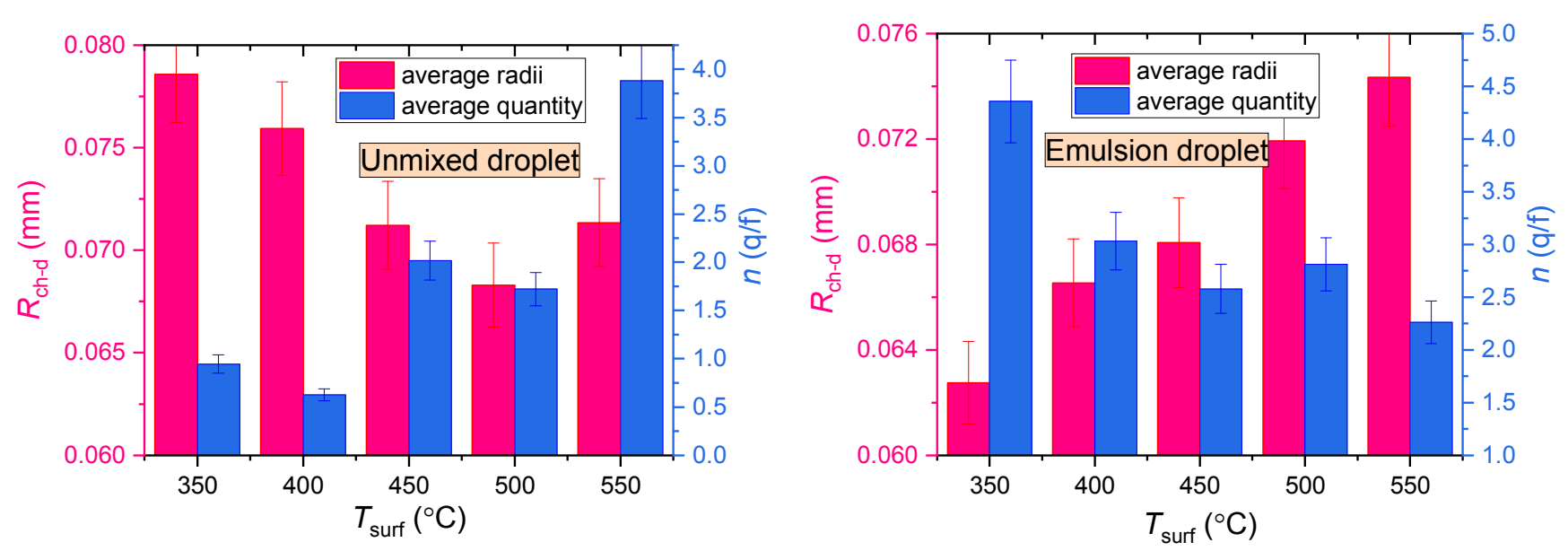

Fig. 14. Average size and number of child droplets resulting from the micro-explosion of emulsion droplets and immiscible two-component droplets with varying temperature surface ( $\left.T_{\text {surf }}\right)$ obtained using schlieren photography.

Key comments on the comparative analysis of the results obtained by schlieren photography (Fig. 14):

- as mentioned above for emulsion droplets, the destruction process is overall rather stable. However, Fig. 14 shows that the specific average number of droplets goes down, whereas their average radius goes up. What is special about the micro-explosion of emulsion droplets is that at the initial stage, it is a stable emulsion of a combustible component and micro-droplets of water. When heated, water micro-droplets grow larger by coalescing with each other. By the time the droplet explodes, 10 to 20 water fragments circulate in it [14]. Micro-explosion is usually triggered by the instantaneous boiling and atomization of these fragments. The higher the temperature $T_{\text {surf, }}$, the faster and more active the coalescence of water micro-droplets within the main droplet. Thus, at high temperatures there are fewer local centers of water boiling within the main droplet than at lower temperatures. A decrease in the number of boiling centers leads to a less intense explosive breakup and hence to a decrease in the number of child droplets and a slight increase in their average radius;

- for immiscible two-component droplets we observe the opposite trend as compared to the emulsion [14]. At the initial stage, the main droplet contains just one water fragment. When the droplet is heated, it breaks up into numerous droplets. The higher the $T_{\text {surf }}$, the faster the process and the more micro-droplets are formed within the main droplet. That is why more child droplets emerge and their average radius becomes smaller with an increase in $T_{\text {surf }}$ for an immiscible twocomponent droplet (opposite trend). 

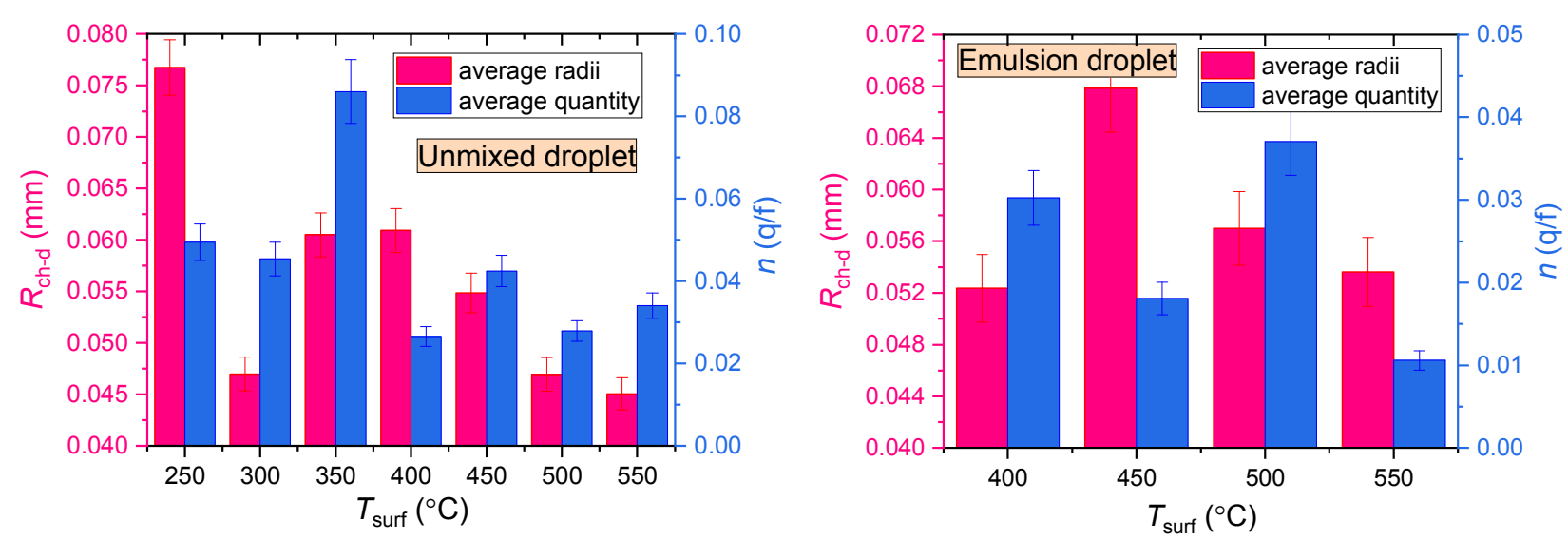

Fig. 15. Average size and number of child droplets resulting from the micro-explosion of emulsion droplets and immiscible two-component droplets with varying surface temperature ( $\left.T_{\text {surf }}\right)$ obtained using laser illumination.

Key comments on the comparative analysis of the results obtained by laser illumination (Fig. 15):

- for immiscible two-component droplets we observe spikes in the values of $R_{\text {ch-d }}$ and $n$ at the temperatures $T_{\text {surf }}=250-300{ }^{\circ} \mathrm{C}$. Just as before, this can be explained by the fact that we often observe the first case of the Explosion regime (Fig. 7) with these parameters. This case is notable for the aspects presented in Table 2. The droplet size is reduced by the moment of microexplosion, which leads to the result being analyzed. At $T_{\text {surf }}=350-550{ }^{\circ} \mathrm{C}$, we observe a reduction in $R_{\text {ch-d }}$ due to the intensified micro-explosion (growth of local vaporization centers). The number of water droplets decreases (on the contrary to Fig. 14) due to the intense water evaporation in the course of droplet heating. The higher the surface temperature $T_{\text {surf, }}$ the higher the mass evaporation rate.

- for emulsion droplets, it can be seen (Fig. 15) that the average number of secondary water droplets almost does not change, remaining in the range of $n=0.2-0.25$. The average radius becomes overall smaller. There may be several reasons for this trend. First, water micro-droplets are rather evenly distributed in the emulsion. The contact with the heated substrate leads to their enlargement (coalescence) [29, 36, 37] and intensifies the movement within the droplet. An increase in the substrate temperature accelerates these processes but does not change the mechanism and the overall patterns. Therefore, the number of secondary droplets changes negligibly. Presumably, in order to ensure the breakup of an emulsion droplet, it is enough to have a certain threshold number of large water droplets that are superheated up to the boiling temperature and break up. In experiments with immiscible two-component droplets, we observed the opposite trend: a large local volume of water dispersed to form small water droplets within the combustible component. Before the micro-explosive breakup, the emulsion droplets and immiscible two-component droplets looked almost identical, i.e., a number of water droplets of 
different sizes were observed within the combustible component. A certain portion of these droplets were superheated and boiled: the fragmentation in the puffing or micro-explosion regime was intensified.

Fig. 16 gives the average total volume of child droplets $\left(V_{\text {sum }}\right)$ in a frame produced from the micro-explosion of emulsion droplets and immiscible two-component droplets. The value of $V_{\text {sum }}$ was given by:

$$
V_{\text {sum }}=4 / 3 \cdot \pi\left(R_{\text {ch-d(1) }}^{3} \cdot N_{\mathrm{pf}(1)}+R_{\text {ch-d(2) }}^{3} \cdot N_{\mathrm{pf}(2)}+\ldots+R_{\text {ch-d(i) }}^{3} \cdot N_{\mathrm{pf}(\mathrm{i})}\right)
$$

\subsection{Child droplet volumes and volume fractions}

The calculation of $V_{\text {sum }}$ is necessary to determine the relative volume fraction of water droplets within a group of child droplets. Overall, Fig. 16 confirms the conclusions drawn from the analysis of Figs. 12-15. Schlieren photography makes it possible to determine the average size and number of all the droplets (including the combustible component and water). Laser illumination allows us to record the same parameters but only for water droplets. Thus, we can calculate the proportion of water droplets in the overall number of child droplets.
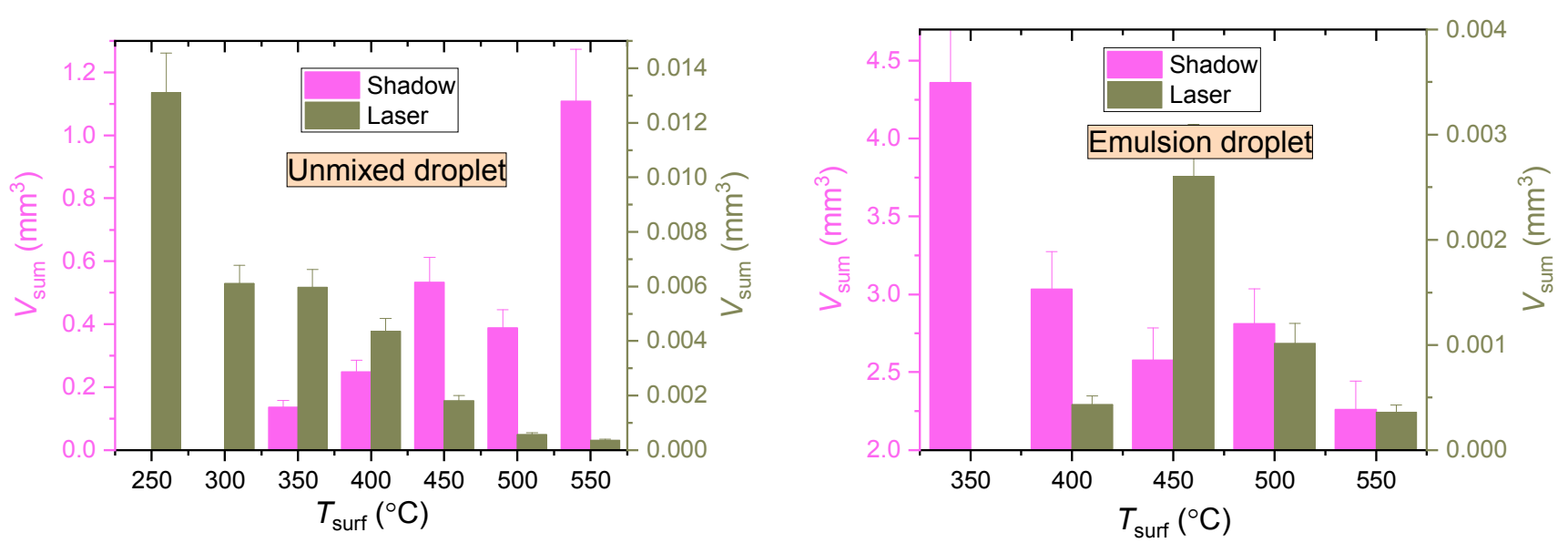

Fig. 16. Average total volume of child droplets resulting from the micro-explosion of emulsion droplets and immiscible two-component droplets with varying temperature of the heated surface ( $\left.T_{\text {surf }}\right)$ obtained using laser illumination and schlieren photography.

Fig. 17 gives the percentage of water droplets in the total number of the emerging child droplets. At the same time, Fig. 17 illustrates both the share of child droplets derived from the average number of droplets $-n$ (Figs. 14 and 15) and volume fraction of droplets derived from the total average volume of droplets in the observational area $-V_{\text {sum }}$ (Fig. 16). The results are given for the experiments with emulsion droplets and immiscible two-component droplets. At the same time, with the equal size of the observation area, the depth of focus was different for schlieren photography and laser illumination. The light sheet was about $0.5 \mathrm{~mm}$ thick and the focal depth of the lens during schlieren photography is approx. 
$1.5 \mathrm{~mm}$. Thus, when calculating the proportion of water droplets in the total number or total volume of child droplets, we multiplied their number by $1.5 / 0.5=3$.
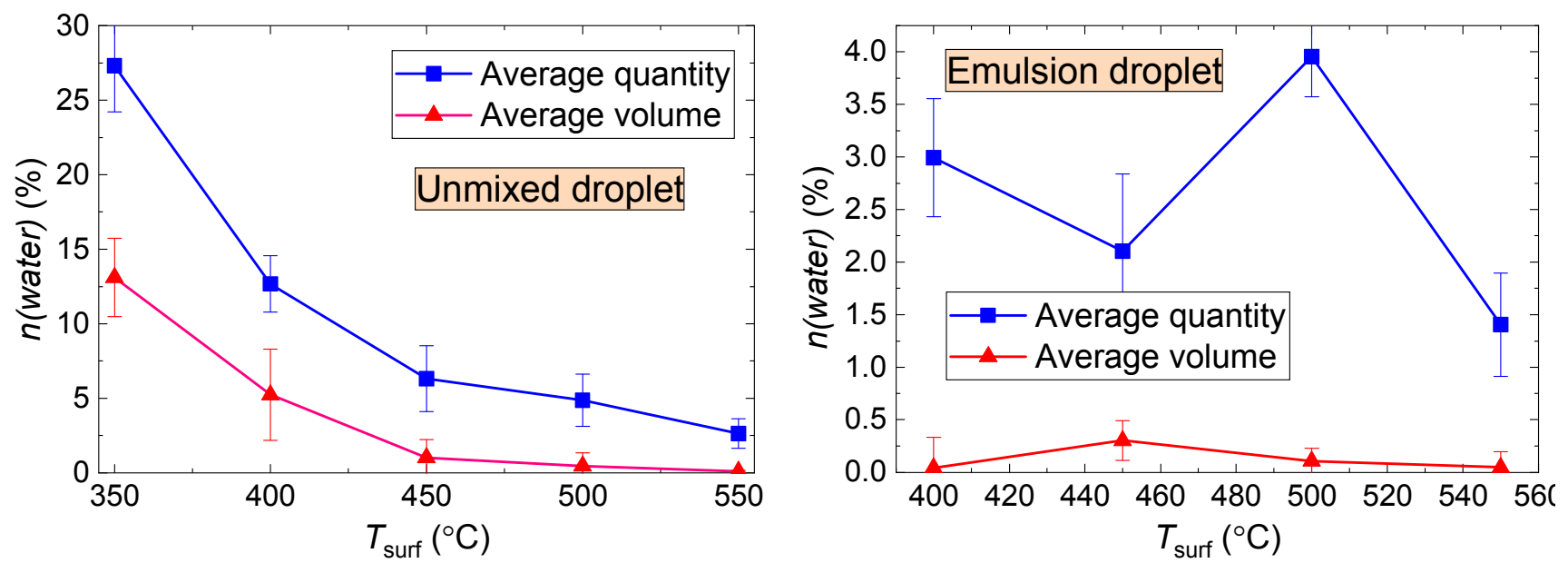

Fig. 17. Relative percentage of water droplets in the total number of emerging child droplets (for emulsion droplets and immiscible two-component droplets) derived from their average quantity and average volume fraction.

For two-component immiscible droplets, we observed a stable trend of a decrease in the number of secondary water droplets with an increase in the substrate temperature, whereas the experiments with prefabricated emulsion droplets did not show this trend (Fig. 17). The whole volume of water is heated up to a relatively high temperature when an immiscible two-component droplet contacts the heated surface. The higher the $T_{\text {surf }}$, the higher the temperature that the water reaches in the immiscible two-component droplet. This accelerates its evaporation. The droplets breaking off evaporate quickly and the values of $n$ (water) go down. In the experiments with emulsion droplets, we recorded highly heterogeneous temperature fields of droplets before micro-explosion. They characterized different temperatures of water droplets within the combustible component. Thus, droplets that were more heated evaporated quickly and the rest evaporated slowly. Water droplets in the emulsion moved rather chaotically, so the proportion of water droplets also changed chaotically when the substrate temperature was increased (Fig. 17). However, the overall trend remained - the volume fraction of water decreased with an increase in the substrate temperature.

Overall, the analysis of Fig. 17 shows that the best approach to analyzing the proportion of water droplets within a cloud of child droplets is by using their volume fraction. Thus, for instance, for immiscible two-component droplets, the parameter $n$ exceeds the original concentration of $9 \%$ only at $T_{\text {surf }}=350^{\circ} \mathrm{C}$. This happens because the second type of the Explosion regime occurs most frequently at these temperatures. In this type, a large proportion of the combustible component may fly away beyond the frame boundaries as large fragments. For this reason, we may observe the case when $n>9 \%$. For the emulsion droplets, however, water droplets are distributed rather evenly in the combustible component. 
As a result, not all of them are superheated to the boiling temperature but only those located in the lower part of the droplet (closer to the substrate). Thus, there are much fewer water droplets among the secondary fragments in the experiments with the emulsion.

\subsection{Child droplet velocities}

Fig. 18 gives examples of how the average velocities $\left(U_{\text {ch-d }}\right)$ of child droplets change over time when immiscible two-component droplets break up (for the Explosion regime) at different temperatures of the heated surface ( $\left.T_{\text {surf }}\right)$. When analyzing the data obtained, we could see quite a wide range of velocities $U_{\text {ch-d. }}$ It does not only depend on the heating temperature and type of droplet but also on the conditions of its contact with the heated substrate. The longer the initial droplet is heated, the greater the velocities of the secondary fragments breaking off from it. Moreover, their size usually decreases significantly with an increase in $T_{\text {surf. }}$ As a result, the aerodynamic drag forces acting on the secondary droplets decrease significantly as well. This contributes to the growth of distances covered by the secondary droplets and to a significant decrease in their size due to intense heating.
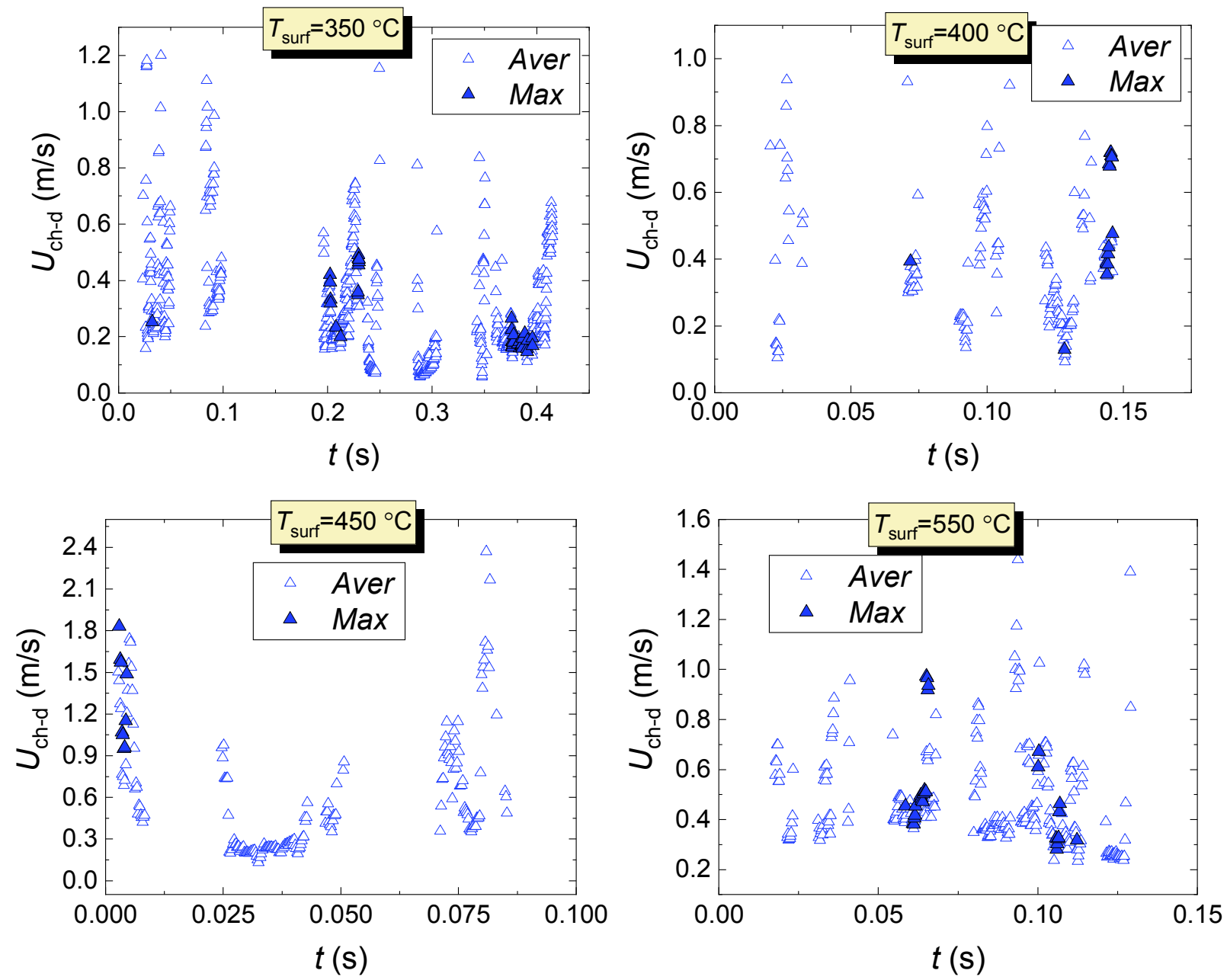

Fig. 18. Average velocities of child droplets (Max - maximum; Aver - average) resulting from the breakup of immiscible two-component droplets (in the Explosion regime) over time at different temperatures of the heated surface $\left(T_{\text {surf }}\right)$. 


\subsection{Generalization of research findings}

Fig. 19 shows the temporal variation of the average temperatures $\left(T_{\text {ch-d }}\right)$, velocities $\left(U_{\text {ch-d }}\right)$ and distances of child droplets from the substrate $\left(L_{\mathrm{ch}-\mathrm{d}}\right)$ during the destruction of immiscible two-component droplets for several groups of child droplet sizes. Clearly, the velocity of secondary droplets goes down as they move further away from the substrate. This is conditioned by both the gravitational forces and slowing down due to the intense evaporation and entrainment by the convective fluxes. Moreover, the convective heat fluxes provide extra heating for the droplets as they move away from the substrate. This intensifies the droplet shrinkage due to the rapid evaporation. The larger the original size of the secondary droplets, the stronger the trends (Fig. 19).

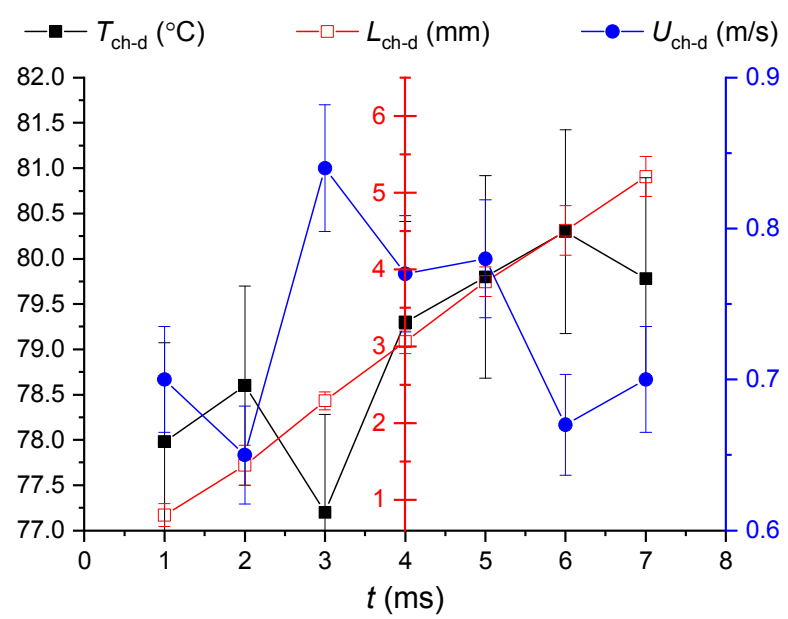

$a$

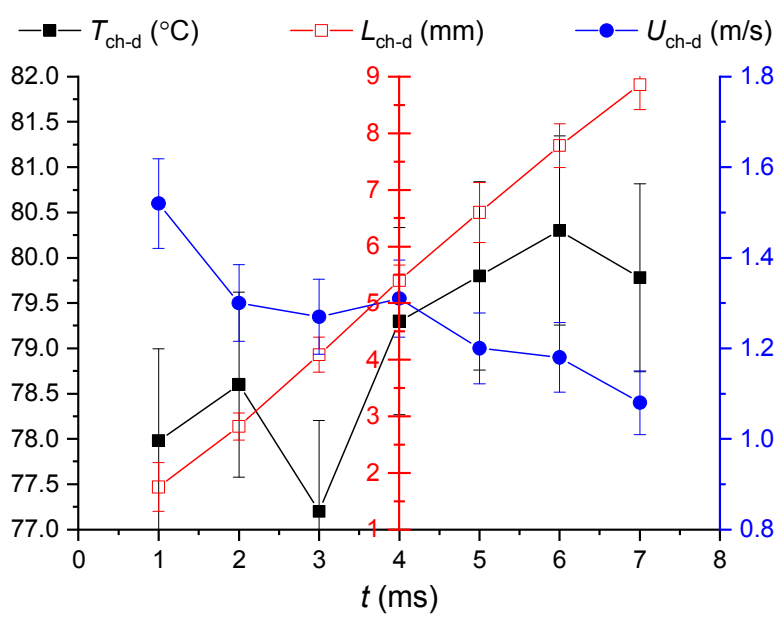

$b$

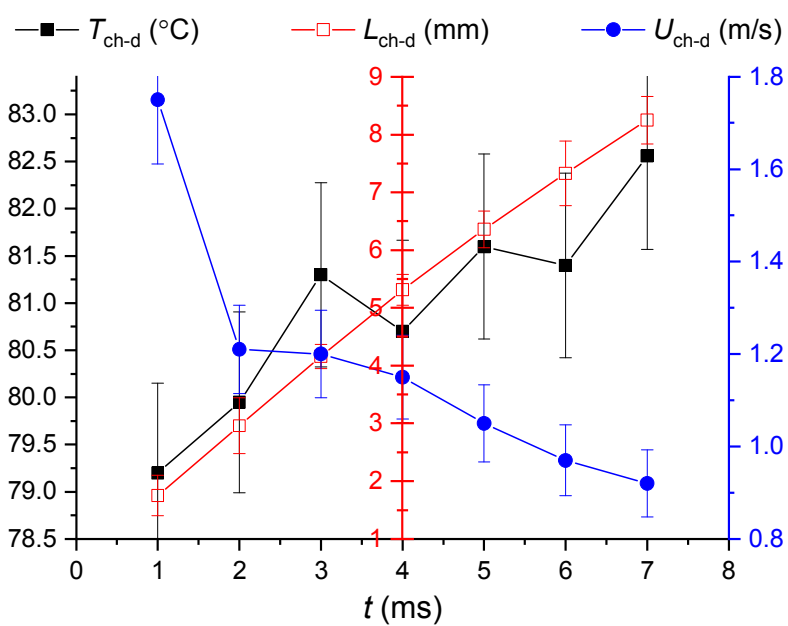

$c$

Fig. 19. Temporal variation of the average temperatures $\left(T_{\text {ch-d }}\right)$, velocities $\left(U_{\text {ch-d }}\right)$, and distances $\left(L_{\text {ch-d }}\right)$ of child droplets from the substrate during the destruction of immiscible two-component droplets in the Explosion regime for $T_{\text {surf }} \approx 450{ }^{\circ} \mathrm{C}: a$ - for droplets with $R_{\text {ch-d }}=0.02-0.03 \mathrm{~mm} ; b$ - for droplets with $R_{\text {ch- }}$ d $=0.03-0.08 \mathrm{~mm} ; c-$ for droplets with $R_{\text {ch-d }}=0.08-0.2 \mathrm{~mm}$. 
Fig. 20 shows the average temperatures $\left(T_{\text {ch-d }}\right)$, velocities $\left(U_{\text {ch-d }}\right)$, radii $\left(R_{\text {ch-d }}\right)$, and kinetic energies of child droplets $\left(E_{\text {ch-d }}\right)$ resulting from the breakup of immiscible two-component droplets in the Explosion regime over time at different temperatures of the heated surface ( $\left.T_{\text {surf }}\right)$. The curves given can be regarded as the generalized research findings. They show a clear link between the droplet size and velocity: the smaller the droplets, the higher their velocities, and vice versa. The temperature of secondary droplets, however, largely depends on the duration of the parent droplet's contact with the substrate, i.e., the micro-explosion delay time (Fig. 11). Therefore, to produce a high-temperature aerosol cloud, it is rational to maintain the limited heating temperatures. However, to produce a fine mist with high kinetic energy, the substrate temperature should be increased. At the same time, the minimal (threshold) substrate temperatures, at which the micro-explosion occurs consistently, are enough given the overall small differences $\left(2-3{ }^{\circ} \mathrm{C}\right)$ between the temperature of secondary droplets in Fig. $20 a$ for the range of $T_{\text {surf }}=250-550^{\circ} \mathrm{C}$ and high heating rate of small secondary droplets. When further heated, the secondary droplets will break up extensively and the size distribution of the mist aerosol will go down.

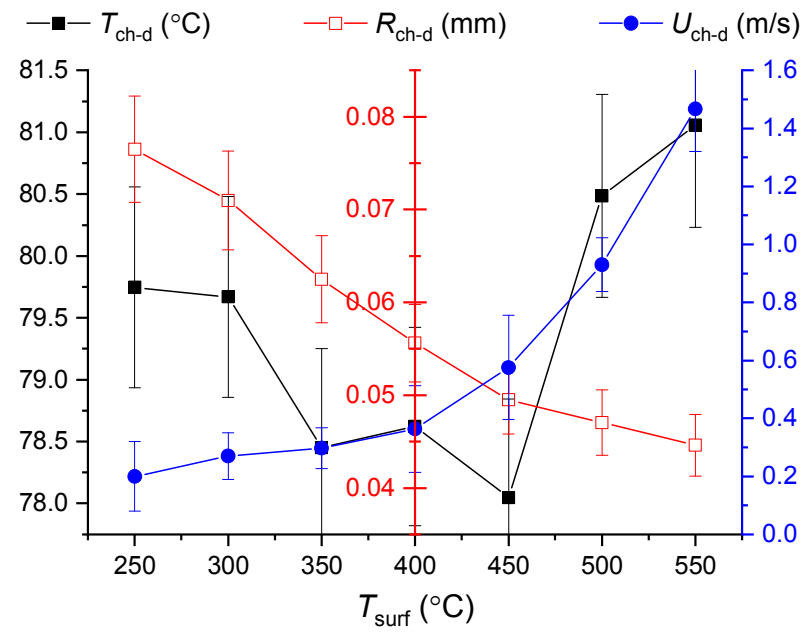

$a$

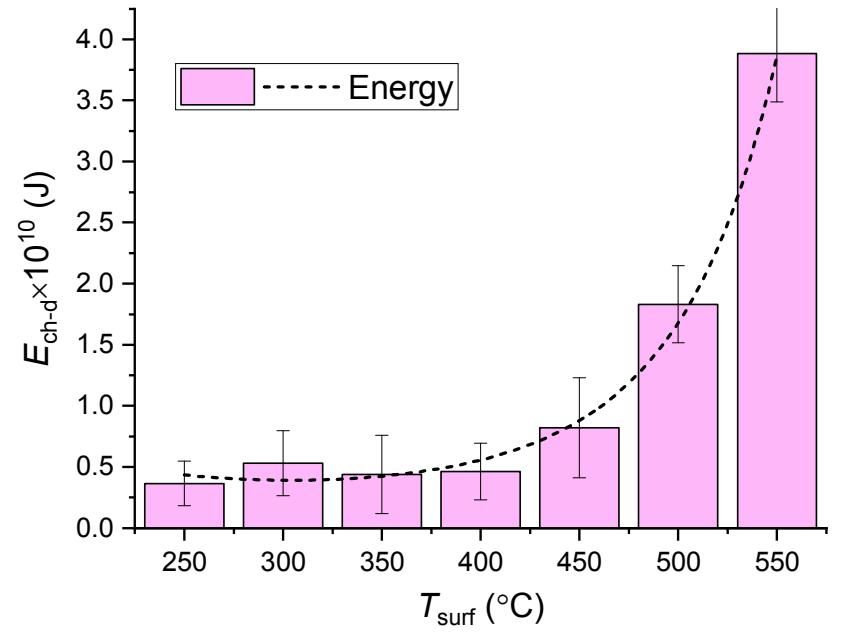

$b$

Fig. 20. $a$ - average temperatures $\left(T_{\text {ch-d }}\right)$, velocities $\left(U_{\text {ch-d }}\right)$ and radii $\left(R_{\text {ch-d }}\right)$ of child droplets resulting from the breakup of immiscible two-component droplets in the Explosion regime over time at different temperatures of the heated surface $\left(T_{\text {surf }}\right) ; b$ - average kinetic energies of one child droplet $\left(E_{\text {ch-d }}\right)$ produced from the breakup of immiscible two-component droplets in the Explosion regime over time at different temperatures of the heated surface $\left(T_{\text {surf }}\right)$.

The experimental findings of this research give a deeper insight into the processes involved in the micro-explosive fragmentation of liquid droplets [1-16]. In particular, the comprehensive analysis has shown the variation ranges of the key parameters of secondary droplets produced from the microexplosive breakup of the initial two-component droplets. The parameters of child droplets are important as a proof that micro-explosive breakup holds great promise as one of the ways to ensure the secondary atomization of liquid droplets directly in the combustion chamber. This atomization should be intensified 
in the combustion chamber to minimize the modifications of spraying systems, prevent the entrainment of a large number of droplets onto the chamber walls, and control the mixing of fuel jets with different component compositions. This will ensure droplet atomization and a uniform filling of the chamber with the vapors of combustible and noncombustible components. Moreover, this will also make it possible to limit the anthropogenic gas emissions and control the physical and chemical underburning.

\section{Conclusions}

(i) The experiments allowed us to compare the integral characteristics of secondary droplets (number, sizes, velocities, trajectories, temperatures, and component composition) for two types of parent droplets that differ greatly from each other at the initial heating stage: emulsion droplets with mixed components and immiscible two-component droplets with a water core and a combustible envelope. With an increase in the temperature of the heated surface $\left(T_{\text {surf }}\right)$, the average size of child droplets produced from the breakup of immiscible two-component droplets goes down and their number increases. The emulsion droplets exhibit the opposite behavior. We have established the conditions for the production of a fine mist from the micro-explosive breakup of droplets in different original states.

(ii) Using a combination of Schlieren Photography, Particle Tracking Velocimetry, and 2-Color LIF, we have identified the liquid fragments representing water and the combustible component in child droplets. It is established that the average size of child droplets corresponding to water is on average 10$15 \%$ smaller than the total average size of the emerging child droplets. With an increase in the surface temperature $\left(T_{\text {surf }}\right)$, the average proportion of child droplets corresponding to water produced from the immiscible two-component droplets goes down in the range of $27 \%$ to $3 \%$. For the emulsion droplets, this number remains at the same level of about $2.5 \%$. With an increase in the temperature of the heated surface in the range of $T_{\text {surf }}=250-550{ }^{\circ} \mathrm{C}$, the average size of child droplets decreases by more than $100 \%$, from the original $0.07 \mathrm{~mm}$ down to $0.03 \mathrm{~mm}$, the average velocity of child droplets increases by more than 7 times (from $0.2 \mathrm{~m} / \mathrm{s}$ to $1.5 \mathrm{~m} / \mathrm{s}$ ), and the kinetic energy of child droplets increases significantly as well (the most large-scale growth is observed at $T_{\text {surf }}>450{ }^{\circ} \mathrm{C}$ ).

(iii) The analysis of child droplet temperatures has given rather interesting results. In particular, with an increase in the temperature of the heated surface ( $\left.T_{\text {surf }}\right)$, the average temperature of child droplets goes down, because the droplet remains on the heated substrate for a shorter time. However, the temperatures $T_{\text {ch-d }}$ increase at $T_{\text {surf }}>450{ }^{\circ} \mathrm{C}$. Generally, the temperature of child droplets $T_{\text {ch-d }}$ is directly proportional to the time $t_{\mathrm{e}}$. The temperature of child droplets $T_{\text {ch-d }}$ increases by $1-8{ }^{\circ} \mathrm{C}$ as they move away from the parent droplet because they are heated by the hot air ascending from the heated surface.

(iv) The research findings will contribute significantly to the development of micro-explosive breakup technology, since they describe the conditions, in which it is possible to ensure the production of a fine mist of high-temperature secondary fragments. The latter will trigger the secondary atomization of 
droplets with different component compositions in the combustion chambers. In this research, we have established that a high-temperature fine mist aerosol can be produced under minimal critical conditions of micro-explosion, i.e., there is no need to use intense heating with high energy consumption. Thus, the production of a cloud of child droplets with the required characteristics (size, velocity, trajectories, component composition, and kinetic energy) can be optimized if it is reproduced in combustion chambers of real-life power plants and engines.

\section{Acknowledgments}

The work on the paper was supported by the National Research Tomsk Polytechnic University (contributions by Pavel Strizhak, Roman Volkov) and by the Région Pays de la Loire: Chaire Connect Talent ODE (contributions by Omar Moussa, Dominique Tarlet, Jérôme Bellettre).

\section{References}

1. O. Moussa, D. Francelino, D. Tarlet, P. Massoli, J. Bellettre, Insight of a water-in-oil emulsion drop under Leidenfrost heating using laser-induced fluorescence optical diagnostics: At. Sprays 29(1) (2019) 1-17. https://doi.org/10.1615/AtomizSpr.2019029233

2. L. Wang, J. Wang, X. Qiao, D. Ju, Z. Lin, Effect of ambient temperature on the micro-explosion characteristics of soybean oil droplet: The phenomenon of evaporation induced vapor cloud, Int. J. Heat Mass Transf. 139 (2019) 736-746. https://doi.org/10.1016/j.ijheatmasstransfer.2019.04.038

3. Z. Nissar, O. Rybdylova, S.S. Sazhin, M. Heikal, A. Rashid B.A. Aziz, M.A. Ismael, A model for puffing/microexplosions in water/fuel emulsion droplets, Int. J. Heat Mass Transf. 149 (2020) 119208. https://doi.org/10.1016/j.ijheatmasstransfer.2019.119208

4. B. Kichatov, A. Korshunov, A. Kiverin, A. Saveliev, The role of explosive boiling in the process of foamed emulsion combustion, Int. J. Heat Mass Transf. 119 (2018) 199-207. https://doi.org/10.1016/j.ijheatmasstransfer.2017.11.116

5. D. Tarlet, E. Mura, C. Josset, J. Bellettre, C. Allouis, P. Massoli, Distribution of thermal energy of child-droplets issued from an optimal micro-explosion, Int. J. Heat Mass Transf. 77 (2014) 10431054. https://doi.org/10.1016/j.ijheatmasstransfer.2014.06.054

6. D. Tarlet, C. Josset, J. Bellettre, Comparison between unique and coalesced water drops in microexplosions scanned by differential calorimetry, Int. J. Heat Mass Transf. 95 (2016) 689-692. https://doi.org/10.1016/j.ijheatmasstransfer.2015.12.054

7. D. Tarlet, C. Allouis, J. Bellettre, The balance between surface and kinetic energies within an optimal micro-explosion, Int. J. Therm. Sci. $107 \quad$ (2016) 179-183. https://doi.org/10.1016/j.ijthermalsci.2016.04.008 
8. O. Moussa, D. Tarlet, P. Massoli, J. Bellettre, Investigation on the conditions leading to the microexplosion of emulsified fuel droplet using two colors LIF method, Exp. Therm. Fluid Sci. 116 (2020) 110106. https://doi.org/10.1016/j.expthermflusci.2020.110106

9. R.S. Volkov, P.A. Strizhak, Using Planar Laser Induced Fluorescence to explore the mechanism of the explosive disintegration of water emulsion droplets exposed to intense heating, Int. J. Therm. Sci. 127 (2018) 126-141. https://doi.org/10.1016/j.ijthermalsci.2018.01.027

10. D. V. Antonov, P.A. Strizhak, Heating, evaporation, fragmentation, and breakup of multi-component liquid droplets when heated in air flow, Chem. Eng. Res. Des. (2019) https://doi.org/10.1016/j.cherd.2019.03.037

11. D.V. Antonov, M.V. Piskunov, P.A. Strizhak, Explosive disintegration of two-component drops under intense conductive, convective, and radiant heating, Appl. Therm. Eng. 152 (2019) 409-419. https://doi.org/10.1016/j.applthermaleng.2019.02.099

12. C. Cen, H. Wu, C. Lee, L. Fan, F. Liu, Experimental investigation on the sputtering and microexplosion of emulsion fuel droplets during impact on a heated surface, Int. J. Heat Mass Transf. 132 (2019) 130-137. https://doi.org/10.1016/j.ijheatmasstransfer.2018.12.007

13. M.Y. Khan, Z.A. Abdul Karim, A. Rashid A. Aziz, M.R. Heikal, C. Crua, Puffing and microexplosion behavior of water in pure diesel emulsion droplets during Leidenfrost effect, Combust. Sci. Technol. 189 (2017) 1186-1197. https://doi.org/10.1080/00102202.2016.1275593

14. P. Strizhak, R. Volkov, O. Moussa, D. Tarlet, J. Bellettre Measuring temperature of emulsion and immiscible two-component drops until micro-explosion using two-color LIF, Int. J. Heat Mass Transf. 163 (2020) 120505. https://doi.org/10.1016/j.ijheatmasstransfer.2020.120505

15. M.M. Avulapati, T. Megaritis, J. Xia, L. Ganippa, Experimental understanding on the dynamics of micro-explosion and puffing in ternary emulsion droplets, Fuel 239 (2019) 1284-1292. https://doi.org/10.1016/j.fuel.2018.11.112

16. Z.A. Abdul Karim, M.Y. Khan, A. Rashid A. Aziz, Evolution of microexplosion phenomenon in parent-child droplets of water in biodiesel emulsions enhanced by different surfactant dosages and hydrophilic-lipophilic balance values, J. Energy Resour. Technol. 141 (2019) 102204. $\underline{\text { https://doi.org/10.1115/1.4043553 }}$

17. Yu. Varaksin, Fluid Dynamics and Thermal Physics of Two Phase Flows: Problems and Achievements, Heat mass transf. phys. gas dynam. $51 \quad$ (3) (2013) 377-407. https://doi.org/10.1134/S0018151X13030073

18. S.S. Sazhin, A.E. Elwardany, P.A. Krutitskii, V. Deprédurand, G. Castanet, F. Lemoine, E.M. Sazhina, M.R. Heikal, Multi-component droplet heating and evaporation: Numerical simulation versus experimental data, Int. J. Therm. Sci. 50 (2011) 1164-1180. https://doi.org/10.1016/j.ijthermalsci.2011.02.020 
19. Y. Hagiwara, S. Sakamoto, M. Tanaka, K. Yoshimura, PTV measurement on interaction between two immiscible droplets and turbulent uniform shear flow of carrier fluid, Exp. Therm. Fluid Sci. 26 (2-4) (2002) 245-252. https://doi.org/10.1016/S0894-1777(02)00133-4

20. D. Damiani, E. Meillot, D. Tarlet, A particle-tracking-velocimetry (PTV) investigation of liquid injection in a DC plasma jet, J. Therm. Spray Technol. 23 (2014) 340-353. https://doi.org/10.1007/s11666-013-0050-5

21. S. Dehaeck, H. Van Parys, A. Hubin, J.P.A.J. Van Beeck, Laser marked shadowgraphy: a novel optical planar technique for the study of microbubbles and droplets, Exp. Fluids, 47 (2009) 333-341. https://doi.org/10.1007/s00348-009-0668-8

22. Y.K. Akhmetbekov, S.V. Alekseenko, V.M. Dulin, D.M. Markovich, K.S. Pervunin, Planar fluorescence for round bubble imaging and its application for the study of an axisymmetric twophase jet, Exp. Fluids, 48 (2010) 615-629. https://doi.org/10.1007/s00348-009-0797-0

23. C. Abram, B. Fond, F. Beyrau, Temperature measurement techniques for gas and liquid flows using thermographic phosphor tracer particles, Prog. Energy Comb. Sci. 64 (2018) 93-156. https://doi.org/10.1016/j.pecs.2017.09.001

24. J. Brübach, A. Patt, A. Dreizler, Spray thermometry using thermographic phosphors, Appl. Phys. B 83 (2006) 499-502. https://doi.org/10.1007/s00340-006-2244-8

25. A. Charogiannis, F. Beyrau, Laser induced phosphorescence imaging for the investigation of evaporating liquid flows, Exp. Fluid. (2013) 54:1518. https://doi.org/10.1007/s00348-013-1518-2

26. T. Xue, S. Zhang, Investigation on heat transfer characteristics of falling liquid film by planar laserinduced fluorescence, Int. J. Heat Mass Transf. $126 \quad$ (2018) 715-724. https://doi.org/10.1016/j.ijheatmasstransfer.2018.05.039

27. F. Xu, G. Hébrard, N. Dietrich, Comparison of three different techniques for gas-liquid mass transfer $\begin{array}{llllllll}\text { visualization, } & \text { Int. } & \text { J. } & \text { Heat } & \text { Mass } & \text { Transf. } & 150 & \text { (2020) }\end{array} 119261$. https://doi.org/10.1016/j.ijheatmasstransfer.2019.119261

28. J. Palmer, L. Schumacher, M.A. Reddemann, V. Kirsch, R. Kneer, Applicability of pulsed 2cLIFEET for micro-droplet internal thermometry under evaporation conditions, Exp. Fluids 61 (2020) 99. https://doi.org/10.1007/s00348-020-2935-7

29. Y. Suzuki, T. Harada, H. Watanabe, M. Shoji, Y. Matsushita, H. Aoki, T. Miura, Visualization of aggregation process of dispersed water droplets and the effect of aggregation on secondary atomization of emulsified fuel droplets, Proc. Combust. Inst. 33-2 (2011) 2063-2070. https://doi.org/10.1016/j.proci.2010.05.115

30. H. Watanabe, T. Harada, Y. Matsushita, H. Aoki, T. Miura, The characteristics of puffing of the carbonated emulsified fuels, Int. J. Heat Mass Transf., 52 (2009) 3676-3684. https://doi.org/10.1016/j.ijheatmasstransfer.2009.02.033 
31. M. Mlkvik, J. Jedelsky, H.P. Karbstein, V. Gaukel, Spraying of viscous liquids: influence of fluidmixing mechanism on the performance of internal-mixing twin-fluid atomizers, Appl. Sci. 10 (2020) 5249. https://doi.org/10.3390/app10155249

32. N. Sharma, W.D. Bachalo, A.K. Agarwal1, Spray droplet size distribution and droplet velocity measurements in a firing optical engine, Phys. Fluids $32 \quad$ (2020) 023304. https://doi.org/10.1063/1.5126498

33. S.G. Daviault, O.B. Ramadan, E.A. Matida, P.M. Hughes, R. Hughes, Atomization performance of petroleum coke and coal water slurries from a twin fluid atomizer, Fuel 98 (2012) 183-193. https://doi.org/10.1016/j.fuel.2012.02.042

34. P. Lua, M. Zhang, Experimental investigation on atomizing characteristics of coal-water paste for pressurized fluidized bed, Fuel 83 (2004) 2109-2114. https://doi.org/10.1016/j.fuel.2004.06.003

35. N. Shlegel, P. Strizhak, D. Tarlet, J. Bellettre, Comparing the integral characteristics of secondary droplet atomization under different situations, Int. Comm. Heat Mass Transf. 108 (2019) 104329. https://doi.org/10.1016/j.icheatmasstransfer.2019.104329

36. E. Mura, P. Massoli, C. Josset, K. Loubar, J. Bellettre, Study of the micro-explosion temperature of water in oil emulsion droplets during the Leidenfrost effect, Exp. Therm. Fluid Sci. 43 (2012) 63-70. https://doi.org/10.1016/j.expthermflusci.2012.03.027

37. J. Shinjo, J. Xia, C. Ganippa, A. Megaritis, Physics of puffing and microexplosion of emulsion fuel droplets, Phys. Fluids 26 (2014) 103302. https://doi.org/10.1063/1.4897918 